\title{
Verified and Validated Design Curves and Strength Reduction Factors for Post-Tensioned Composite Steel-Timber Stiffened Wall Systems
}

\author{
Kristopher Orlowski \\ Centre for Advanced Manufacturing of Prefabricated Housing, Department of \\ Infrastructure Engineering, The University of Melbourne, VIC 3052, Australia \\ kristopher.orlowski@unimelb.edu.au
}

\begin{abstract}
Viability of timber-based solutions for projects is often limited by lengthy modelling and preliminary design when compared to traditional systems such as precast concrete. However, sustainability principles are becoming more prevalent in construction with increasing demands for mid-rise buildings constructed through automated prefabrication via Design for Manufacturing and Assembly (DfMA) techniques. Considering this, this paper introduces and presents design curves for Post-Tensioned (PT) Composite Steel-Timber stiffened wall systems under axial loading. Notably material efficient, they consist of a stiffened engineered timber panel, having half the typical minimum thickness of Cross-Laminated Timber (CLT). Composite action is gained through integrally stiffening the panel with timber studs and steel square hollow sections (SHS), which house a PT rod. The post-tensioning facilitates vertical panel to panel connections for quick onsite assembly, permanent tie-down and self-centering rocking mechanism functionality. A full-scale experimental testing program was conducted in conjunction with analytically verified and validated finite element models. Parametric changes include: level of post-tensioning, number of stiffeners, thickness of panel, height of the wall and applied load. Highly versatile yet simple design curves have been developed from an exhaustive set of incremental results. In addition, a strength reduction factor capturing the effects caused by post-tensioning is proposed. With these, a simple design procedure has been outlined for quick feasibility analysis and preliminary design. That is, for a desired load capacity and level of post-tensioning, the optimal system configurations is given. Likewise, for a chosen configuration and level of post-tensioning the allowable axial load is given.
\end{abstract}

Keywords: Composite Steel-Timber (CST); Post-Tensioned (PT); Design Curves; Cross Laminated Timber (CLT); Automated panelised prefabrication; Snap-through buckling. 


\section{Introduction}

Prefabrication is progressively being adopted in construction, particularly with timber-based systems [1-3] in which industry is furthering its establishment for mid-rise construction through innovation and development $[4,5]$. Traditionally, timber is used in the form of open-panel lightweight frame construction [6, 7] which is generally suitable for low-rise, one to three story, developments [8, 9]. Fundamentally, timber is a renewable material that stores carbon, is highly workable and is suitable for automated prefabrication under via Design for Manufacturing and Assembly (DfMA) [10-17]. This sustainable material can be paired with efficient land development in tall timber construction achieved through what the International Building Code terms as 'massive timber systems', or 'mass wood construction' [18-20]. These use large solid Cross-Laminated Timber (CLT) built-up panels which so far have achieved 18 stories, or 53 meters in height, with structural design concepts that each up to 150 meters [21, 22]. However, a more material efficient timber-based system is required for the practical construction of a new generation of mid-rise buildings. The presented fully prefabricated Post-Tensioned Composite Steel-Timber (PT-CST) stiffened wall system and corresponding design curves and methods may provide a means for this.

Post-tensioning of timber walls suitable for mid-rise buildings was first proposed and studied in 2005 at the University of Canterbury with the development of PresLam technology [23-25]. This and future studies were done showcasing PT based technologies merits in terms of its high seismic performance [26-31]. These studies focused on the lateral stability and seismic performance of basic monolithic timber walls, termed 'mass timber walls' much like precast concrete in terms of its geometrical dimensions. The self-claimed first commercial use of posttensioning in mass timber walls was in 2012, this was a timber alternative solution to posttensioned concrete shear walls with rocking functionality akin to Precast Seismic Structural Systems (PRESS) [32-35]. The PT in mass timber shear walls creates rocking walls of a similar nature [30, 36]. These walls in earthquake events control the damage, provide lateral stability and also facilitate self-centering capability [37]. The timber shear wall used in this leading example was made from mass Laminated Veneer Lumber (LVL) [38]. This has been studied by the University of Canterbury and was first implemented on the 3 story NMIT project located in New Zealand [37]. Since then, this technologies uptake and following studies has been slow, however, it has spurred the resulting shift to post-tensioned mass timber walls being made from CLT instead. Regardless of which type mass timber walls are considered, they are notably thick, at $160 \mathrm{~mm}$ and beyond, which generally matches the thickness of the precast concrete 
alternatives [39]. Although the cross-section dimensions haven't changed significantly, the constituting timber laminates which make these walls are now considerably thicker and crossorientated. Due to the anisotropic nature of timber, the cross-orientation aids the materials use in a shear wall, as it is to resist not just axial, but lateral loads also. From this, mass timber PT walls, also known as self-centering post-tensioned CLT walls are amongst the latest developments in timber engineering and have been studied for their lateral performance in various lateral loading and seismic events [26, 29-31, 37, 40, 41]. Lateral stability and selfcentering characteristics are the primary intended purposes of the inclusion of post-tensioning into these walls, and thus are what has been focused on [30, 36, 42-46]. Experimental investigations to validate the expected lateral response and thus support the outlined premise are plentiful [29-31, 47, 48]. To support the practical implementation of timber systems, numerous studies have provided comprehensive investigation and solutions to fire concerns [49-51]. Primarily, these related to either encapsulating methods or sacrificial char layers [50, 52, 53]. Encapsulation methods include the use of gypsum boards, intumescent coatings and spray applied fire-resistant materials (SFRM) to prevent burning [53-55]. Whereas, with sacrificial char layers, that is, that allowance thereof; the wood is directly exposed such that it can be burnt [54, 56, 57]. The burnt material becomes an insulating charred layer, this in turn controls the rate of burning in a reliable and predictable manner [56, 58, 59]. Despite the advancements in understanding, CLT along with other forms of mass timber construction are often simply material inefficient and expensive, therefore efforts have been made in investigating the effects of replacing some sections of CLT with lightweight framing, particularly with regards to post-tensioning and lateral performance [60]. However, despite all the work on the positive effects of post-tensioning on the lateral performance of mass timber walls, there is a clear gap in research when it comes to the axial performance of timber wall systems under post-tensioning. For vertical loads, the effects of post-tensioning on prefabricated panelised timber walls is a new and relatively unexplored field, and entirely new in terms of the developed Composite Steel-Timber (CST) stiffened walls [61]. This hinders the design, development and adoption of these more sustainable minded systems in industry, particularly when compared to more traditional and widespread construction systems such as precast concrete. There are many factors which relate to the viability and feasibility of a timberbased solution for a project. One such factor is the ability to undertake rapid modelling and preliminary design in the early stages $[62,63]$. Time intensive purpose and project specific finite element modelling (FEM) and specialist knowledge at this early stage makes more traditional methods based on concrete and steel more attractive options in terms of perceived 
viability [24, 64-66]. Due to its novelty there is currently no adequate procedure in national or international standards or guidelines to specifically cater for the design of Post-Tensioned Composite Steel-Timber (PT-CST) stiffened wall systems under axial load. A means for the rapid assessment of the capacity and identification of optimal design of commercially competitive configurations of Post-Tensioned Composite Steel-Timber (PT-CST) stiffened wall systems is needed.

\section{Post-Tensioned Composite Steel-Timber Stiffened Wall Systems}

The developed Post-Tensioned (PT) Composite Steel-timber (CST) stiffened wall system is displayed in Figure 1. It consists of a moderately thick engineered timber panel which is integrally stiffened through a chemically bonded and mechanically fastened connection to sawn-cut timber studs and steel square hollow sections (SHS) as shown in Figure 2. For clarity, the terminological use of the word post-tensioning is consistent with industry practice, that is, it refers to the tensioning application process being conducted onsite during installation rather than at the manufacturing facility. The composition of different materials allows for the maximization of the benefits of each component and overall material efficiency [67]. The moderate thickness of the engineered timber panel element, $20 \mathrm{~mm}$ to $60 \mathrm{~mm}$, is such that it is lesser than that of the minimum thickness of CLT however significantly greater than typical 6 mm bracing sheets [68-71]. The common minimum thickness of CLT is $60 \mathrm{~mm}$, this is limited by the minimum number of laminated layers, that is, 3 layers of $20 \mathrm{~mm}$ thickness each [39]. However, the typical thickness of CLT used for walls is $160 \mathrm{~mm}$, similar of that to precast concrete [72]. Compared to this thickness, the PT-CST walls consist of a significantly thinner engineered timber panel which is then stiffened and strengthened with conventional sawn cut studs and steel SHS's through a chemical and mechanically fastened connection [73]. The spacing of the sawn cut timber studs is kept constant at $450 \mathrm{~mm}$ in keeping with the traditional spacing in lightweight timber frames [74, 75]. This enables established prefabricators to utilise their existing jigs and automated framing machinery in the manufacture of these systems [7680]. It also ensures that the developed system is fully compatible with off the shelf insulation bats and typical window sizes. Furthermore, this allows the system to be fully compatible with typical flooring systems which have the same $450 \mathrm{~mm}$ spacing for the joists such that a direct load path can be established [81]. 


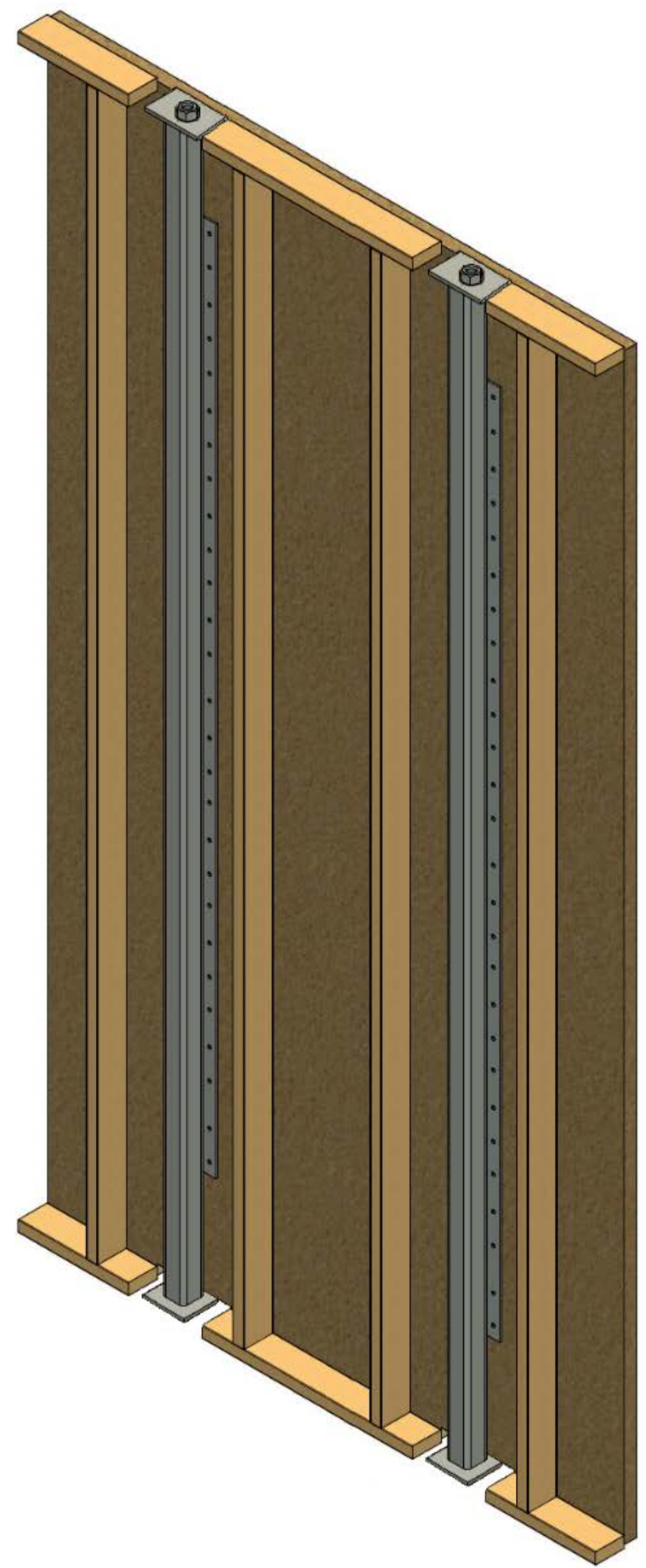

Figure 1. Post-Tensioned (PT) Composite Steel Timber (CST) Stiffened Wall System. 


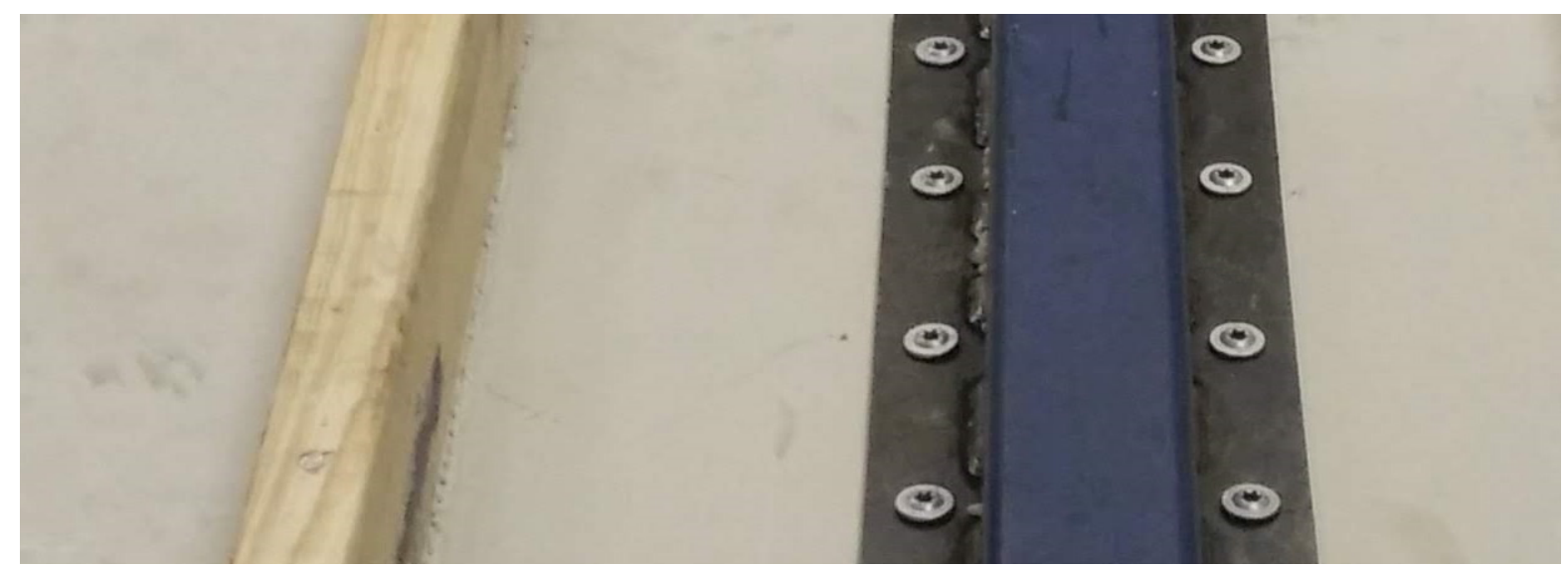

Figure 2. Connection details; nailed and glued stud to panel (left); welded steel tabs and screwed connection of SHS to panel (right).

The proposed array of PT-CST stiffened wall systems consists engineered timber wall panels of varying thicknesses and heights, with a variety of the number of adjacent MGP10 sawn cut timber studs’ stiffeners (e.g. single, double, triple). The term used 'number of studs/stiffeners' refers to the number of adjacent stiffeners per set spacing such as shown in Figure 3. Note that there is no direct connection between adjacent studs, rather, each are glued and nailed to the panel. The rationale behind the proposed design of this system is in the maximisation of current supply chains to increase the feasibility for the practical widespread commercial adoption of the system by taking advantage of common readily available materials, familiarity of methods and construction techniques leading to cost effectiveness.

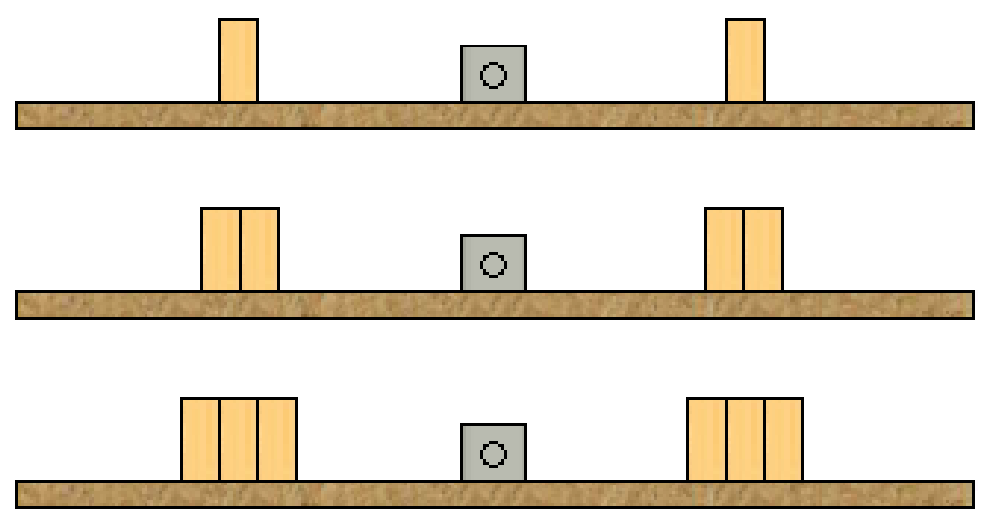

Figure 3. Number of stiffeners 1, 2 and 3 corresponds to single double or triple adjacent studs per set spacing.

The material-efficient nature of the CST stiffened wall allows for a greater resource usage of timber for its load-carrying capability. This is especially notable when a CST stiffened wall is compared to regular rectangular cross-sectioned walls such as CLT since the former has a more efficient distribution of mass about the centroidal axis. For example, a CST stiffened wall with only one $90 \times 35 \mathrm{~mm}$ stud stiffener per $450 \mathrm{~mm}$ and one $65 \times 65 \times 4 \mathrm{~mm}$ SHS per $900 \mathrm{~mm}$ along the length of a $38 \mathrm{~mm}$ engineered timber panel can have the same second moment of 
area as CLT wall of $113 \mathrm{~mm}$ thickness. Apart from stiffening and load carrying, the integrated SHS houses the PT system which consists of a steel rod, end nuts and couplers which takes a critical role as both a connection element and a global structural element braced by the panel. The SHS is embedded into the wall via a glued and screwed connection via welded steel strip tabs, the latter of which aids the former in placement and curing. The inert steel SHS resists the PT loads which is loaded onto it, as a bid to help mitigate against crushing and long-term creep effects which non-hybrid timber post-tensioned structures face [82, 83]. The SHS's are located at set spacings along the length of the wall, with one always at each end of the wall to facilitate a simple bolted plate connection between adjacent walls. Additionally, they serve as secure lifting points during cranage and installation on-site, an example is presented in Figure 4. The PT system stiffens and provides a tied tensioned vertical continuity which helps control the sway of the building through self-centring and helps mitigate structural damage [36, 48]. That is, it acts as the vertical connection for the panelised walls but also ties the entire building to the foundation to prevent overturning $[60,84]$. Through this method, forces induced by extreme winds or earthquakes may be controlled in terms of their potential damaging effect on the building [85, 86]. Moreover, it is important to note that due to the unsymmetrical crosssection (panel on one side only) the tensioned rod lies on the same side of the neutral axis as the overall central loading point. This ensures full mitigation against the risk of snap-through buckling between the temporary and permanent state. A symmetrical configuration with the panel on both sides of the studs would be likely prevent vapour diffusion of the sealed area which may lead rise to an increase risk of condensation, decay and mould growth when built in temperate climates [87-90]. Considering the complexity of the system and the number of components, this study aims to better understand the performance and PT behaviour under vertical axial loading as well as simplify the feasibility analysis and design process of these systems. 


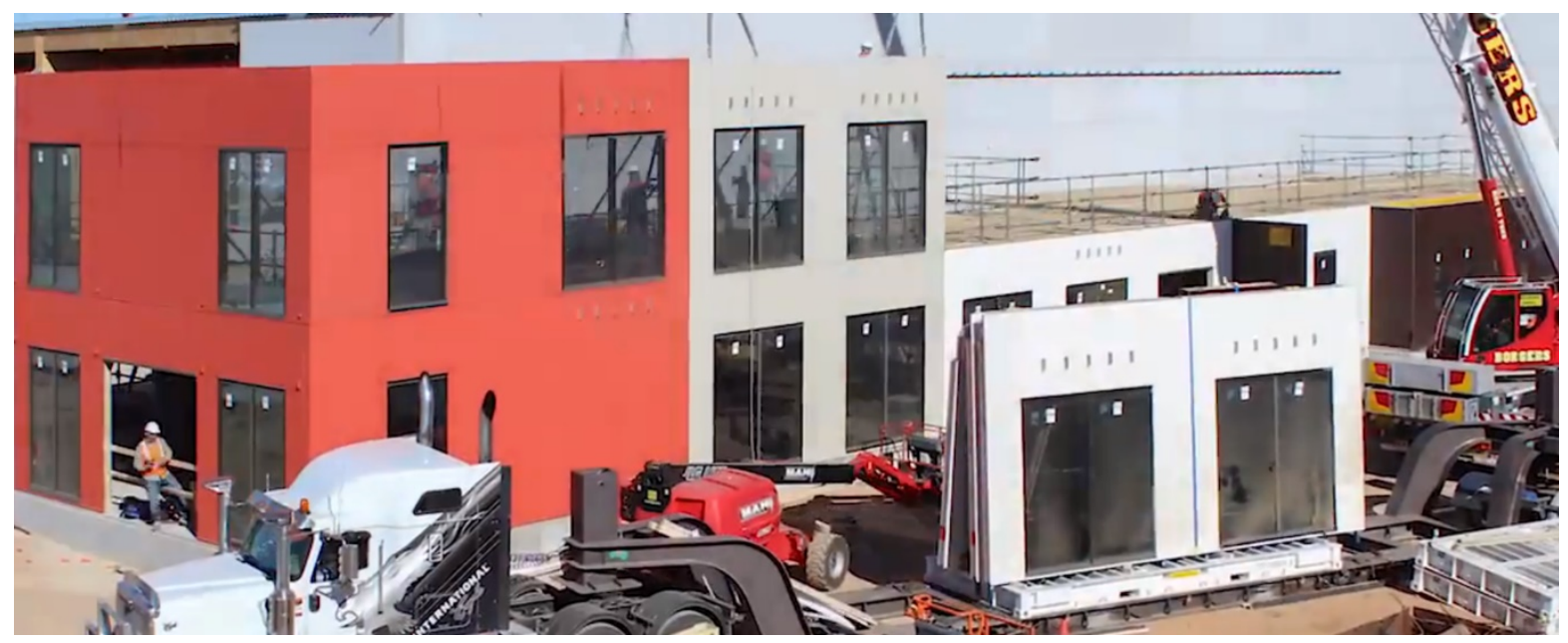

Figure 4. Example of a PT-CST wall system. Note that the walls are fully prefabricated, prior to delivery.

\section{Method and Materials}

\subsection{Overview}

An overview of the method used in this project is presented in Figure 5. A standard configuration of the PT-CST was defined, then a Finite Element Method (FEM) was used to simulate the system which was verified by analytical means. From this, an appropriate experimental setup was configured, and testing occurred. The results of which allowed for the validation of the model which then allowed confident re-simulation across a greater dimensional array. With the key parameters affecting performance found, several altered configurations were designed and manufactured. Walls in accordance to these altered configurations were also then experimentally tested. The results were analysed, and the parametric changes were then again validated the finite element models which were refined in greater detail. The results of which led to the creation of general design curves which can be used for an array of configurations. Additionally, a strength reduction factor due to the application of PT was introduced and evaluated across a range of parameters. Finally, a design procedure has been proposed which makes use of these developed learnings and design resources. Please note that the use of the proposed design method is limited to academic scholarly research in feasibility analysis and initial preliminary design of PT-CST systems that fall within the experimental testing conditions and parametric range investigated. 


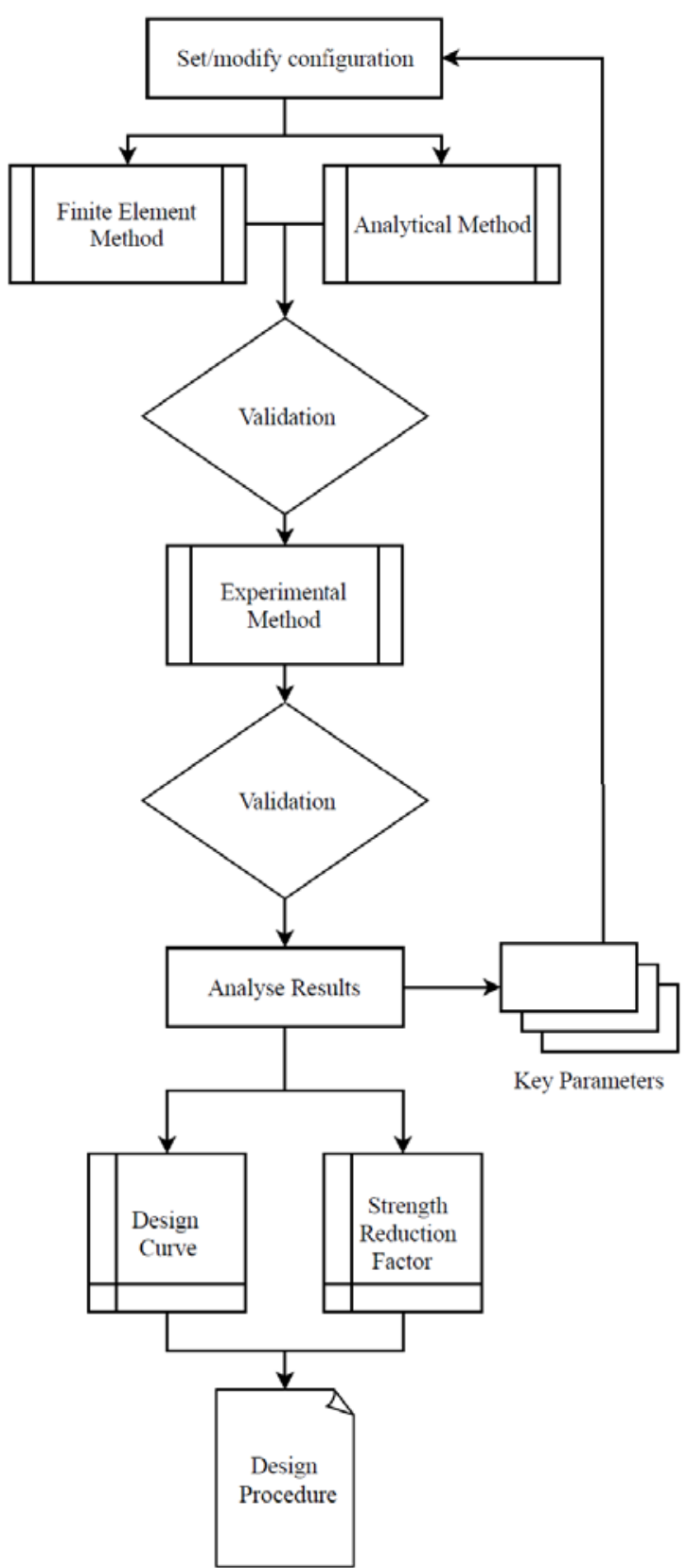

Figure 5. Method used to verify and validate the FEM based on analytical and experimental results.

\subsection{Experimental Program}

\subsubsection{Specimen Design}

As representative sections of a greater width wall, the post-tensioned stiffened engineered timber composite walls specimens in its standard configuration is displayed in Figure 6. All specimens were created in typical prefabricated manufacturing conditions with the aid of an industry partner with the chosen engineered timber panel being Oriented Strand Board (OSB). The detail of each of the constituting elements of the composite walls is summarised in Table 1, with strength classes as per the appropriate standards and certification [91-95]. 
Table 1. Material and geometry summary.

\begin{tabular}{cccc}
\hline Element & Material & Cross section (mm) & Strength \\
\hline Studs & Radiata Pine & $90 \times 35$ & MGP10 \\
Panel & OSB & $900 \times 38$ & OSB4 \\
SHS & Steel & $65 \times 65 \times 4$ & CL450L0 \\
Rod & Steel & $\varnothing 21.7$ & CL300 \\
\hline
\end{tabular}

To ensure stiffness and full composite action at even the early stages of loading, the connection between the relatively flexible panel and the stiffeners is first glued with a one-component polyurethane adhesive having an open time of 45 minutes. Immediately after placement, the studs are then nailed with $130 \mathrm{~mm}$ long, $3.75 \mathrm{~mm}$ diameter nails at $400 \mathrm{~mm}$ centres which ensured even squeeze out. The connection for the SHS component of the PT system to the panel is also first glued with a polyurethane adhesive. It features strips of welded steel tabs to the SHS which provides support for a supplementary screwed connection which is installed immediately after. In both instances, the nails and screws provide clamping pressure which aids the proper spread and bonding of the adhesive during installation and curing.

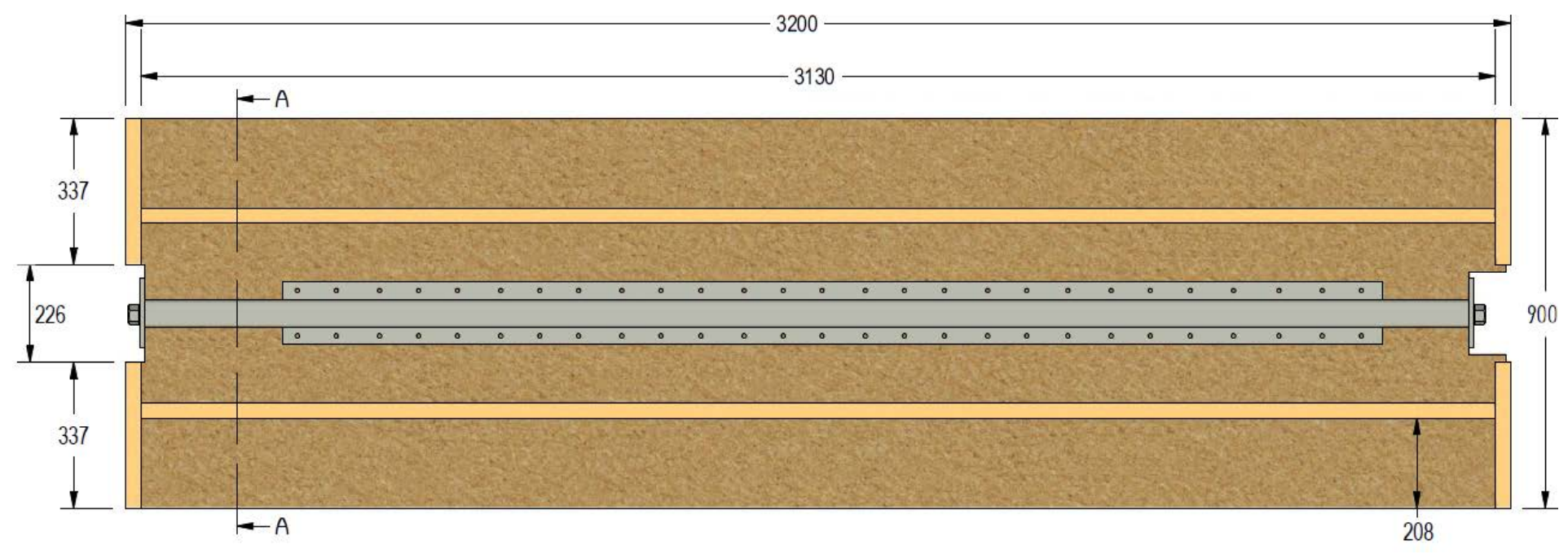

Figure 6. Standard configuration of specimen, units: mm.

The height of the walls in this standard configuration is $3.2 \mathrm{~m}$ with $450 \mathrm{~mm}$ stud spacing and 900 mm PT system spacing, the details of which is summarised in Table 2.

Table 2. Standard configuration specimen summary.

\begin{tabular}{cc}
\hline Property & Specification \\
\hline Wall height & $3.2 \mathrm{~m}$ \\
Panel thickness & $38 \mathrm{~mm}$ \\
Number of adjacent studs per spacing & One \\
Stud spacing & $450 \mathrm{~mm}$
\end{tabular}




$\begin{array}{cc}\text { Studs } & \text { MGP10 } 90 \text { x } 35 \mathrm{~mm} \\ \text { PT spacing } & 900 \mathrm{~mm} \\ \text { PT Rod diameter } & 21.7 \mathrm{~mm} \\ \text { PT Torque level } & 210 \mathrm{Nm} \\ \text { PT force } & \sim 30 \mathrm{kN} \\ \text { SHS } & 65 \times 65 \times 4 \mathrm{~mm} \\ \text { Nail spacing } & 400 \mathrm{~mm} \\ \text { Adhesive } & \text { 1C Polyurethane }\end{array}$

Several other configurations were made identical to the standard configuration apart from a single key modification. Each of which has been carefully selected to investigated and gauge its impact on performance. The parameters which were altered include, height increased from $3.2 \mathrm{~m}$ to $4.0 \mathrm{~m}$, various initial PT forces and also no initial PT force.

Note that the maximum allowed designed PT force is capped at $80 \mathrm{kN}$. This is limited by the maximum amount of force a human can safely apply onsite whilst on a free-standing platform, the yield limit of the steel rod, in this case $137 \mathrm{kN}$, and any potential initial induced bow due to imperfections.

Table 3. Summary of tested walls and their specimen ID.

\begin{tabular}{clcc}
\hline Wall & & \multicolumn{2}{c}{ Characterisation } \\
\cline { 3 - 4 } Number & \multicolumn{1}{c}{ Specimen ID } & Configuration & Description \\
\hline 1 & H3200_PT30_S1 & Standard & Specimen 1 \\
2 & H3200_PT30_S2 & Standard & Specimen 2 \\
3 & H3200_PT30_S3 & Standard & Specimen 3 \\
4 & H3200_PT_0 & Altered & Zero PT force \\
5 & H3200_PT45 & Altered & Increased initial PT force \\
6 & H3200_PT75 & Altered & Increased initial PT force \\
7 & H4000_PT30 & Altered & Altered wall height \\
\hline
\end{tabular}

\subsubsection{Experimental setup, loading and instrumentation}

The experimental setup was conducted in a horizontal manner as depicted in Figure 7. Before external axial load from the actuator is applied, the specimens are post-tensioned to the required initial PT force. This is achievable with a torque wrench, even when the specimen is in the test setup, since the design of the specimen is such that the column is made shorter in this region. This allows the wall to be held still during the PT process thus facilitating accurate reading of any out-of-plane displacement. The initial PT force to be applied to various specimens is $0 \mathrm{kN}$, $30 \mathrm{kN}, 45 \mathrm{kN}$ and $75 \mathrm{kN}$. After post-tensioning, the external axial load is applied only to the studs and SHS. This is achieved by the panel being $10 \mathrm{~mm}$ shorter. Short SHS sections are placed over the torqued nuts to bring the steel column in line with the top and bottom plates. 
This is critical for the external load to be transferred to the SHS rather than the rod. A Material Test Systems (MTS) hydraulic actuator, rated to $500 \mathrm{kN}$, was bolted to the strong floor and applied the external load which was captured by a load cell every 0.01 seconds. The applied load was transferred via a spreader beam to the specimen under displacement control, at a rate of $4.0 \mathrm{~mm} / \mathrm{min}$. This was countered by the butting end in a similar manner. Both ends provided lateral and vertical restraint whilst allowing the specimen to rotate under buckling. Laser triangulation transducers recorded displacements at $100 \mathrm{~Hz}$ were placed underneath the PTCST walls specimens at mid-height.

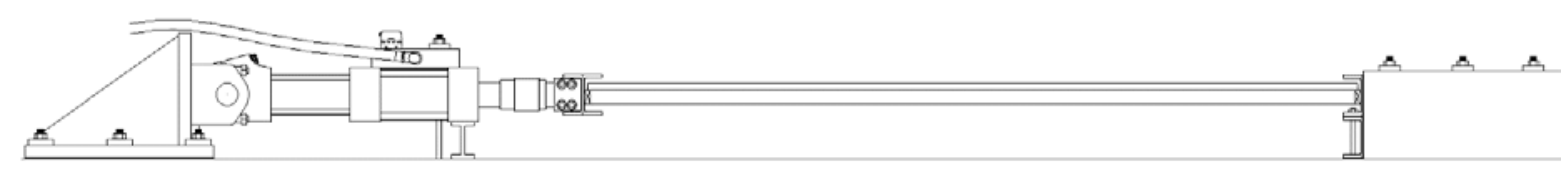

Figure 7. Horizontal experimental setup used for the axial compression tests.

General purpose Tokyo Sokki Kenkyujo [96] strain gauges of type FLA-3-11-3LJC were carefully installed mid-way on the steel PT rods prior to assembly. A calibrated torque wrench with adjustable torque settings was used to apply the post-tensioning force. The level of torque to be applied needs to be calibrated to the level of post-tensioning specified through the strain readings. The strain read was in terms of microstrain and converted to post-tensioning force. Given that the young's modulus of steel of $200 \mathrm{GPa}$ and the rod diameter was $21.7 \mathrm{~mm}$, a linear relationship relating microstrain to the PT force was developed as per Equation 1 and Figure 8 below. From this, the strain readings were matched and paired with the required levels of post-tensioning by increasing torque on the wrench.

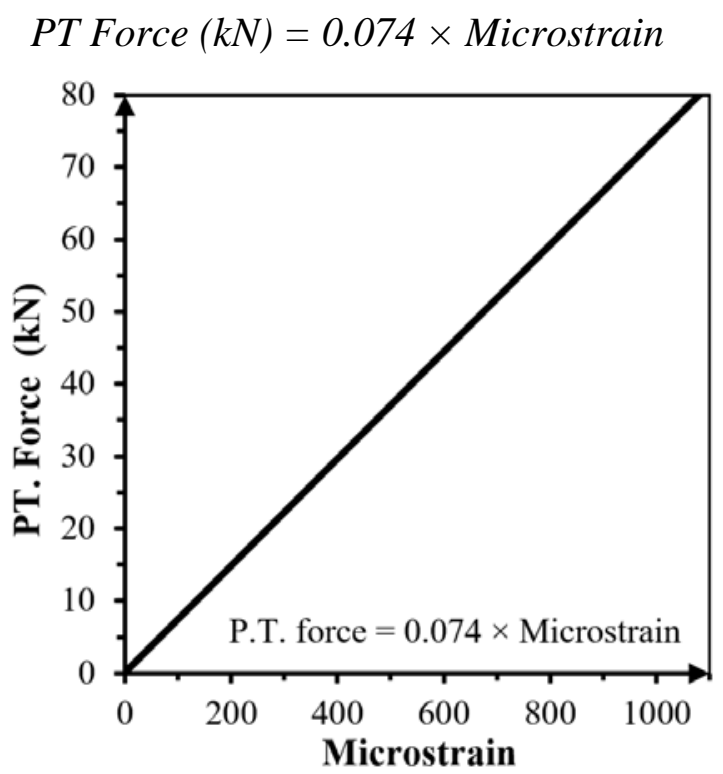

Figure 8. Microstrain to experienced level of post-tensioning. 


\subsection{Analytical}

An analytical method was used to model the behaviour of the composite steel-timber wall systems under axial loading. This was based on the exact Finite Strip Method (FSM). The exact FSM discretises parts in a set of continuous planes, that is in strips [97-99]. The limitation of this is that the geometry must be simple prismatic, that is with regular rectangular sections of uniform cross-sectional area. However, for this application, the panel, timber studs and steel SHS can be simplified into strips and used appropriately as shown in Figure 9.

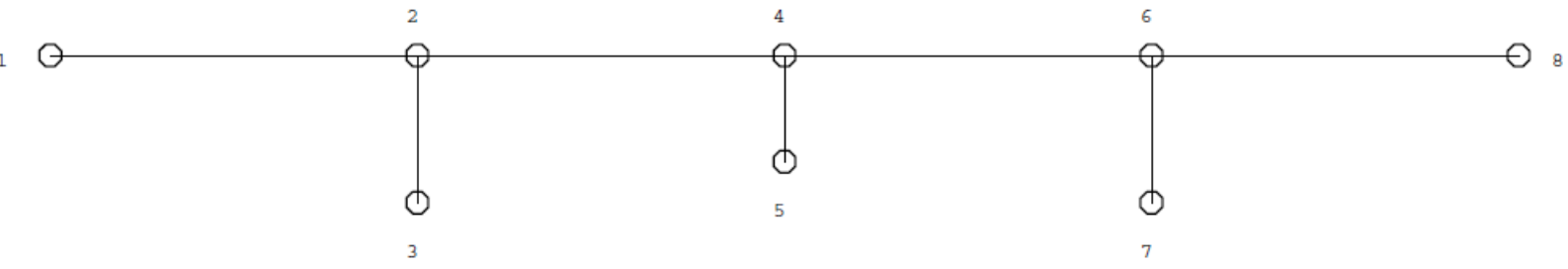

(a)

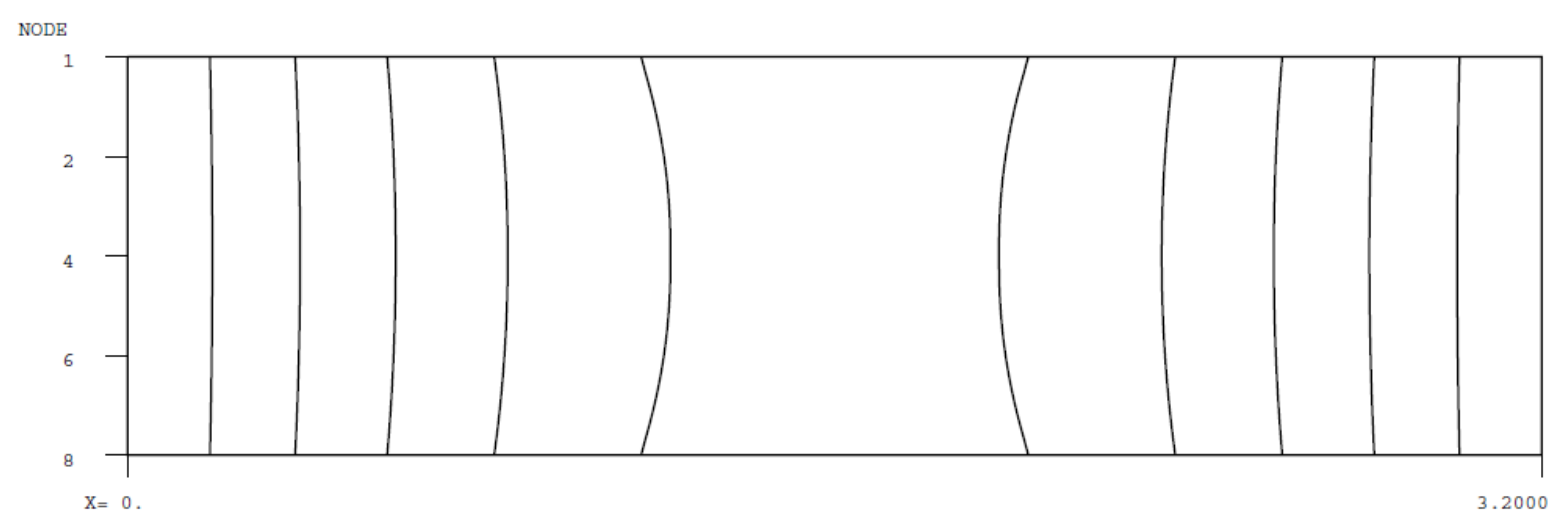

(b)

Figure 9. Strip simplification used for analytical method: (a) profile view; (b) plan view.

Appropriate stiffness matrices were found with the Kirchhoff hypothesis as shown in equation 2 and used for each of the simplified parts.

$$
\left[\begin{array}{c}
\mathrm{N}_{\mathrm{x}} \\
\mathrm{N}_{\mathrm{y}} \\
\mathrm{N}_{\mathrm{xy}} \\
\mathrm{M}_{\mathrm{x}} \\
\mathrm{M}_{\mathrm{y}} \\
\mathrm{M}_{\mathrm{xy}}
\end{array}\right]=\left[\begin{array}{llllll}
\mathrm{A}_{11} & \mathrm{~A}_{12} & \mathrm{~A}_{13} & \mathrm{~B}_{11} & \mathrm{~B}_{12} & \mathrm{~B}_{13} \\
\mathrm{~A}_{12} & \mathrm{~A}_{22} & \mathrm{~A}_{23} & \mathrm{~B}_{12} & \mathrm{~B}_{22} & \mathrm{~B}_{23} \\
\mathrm{~A}_{13} & \mathrm{~A}_{23} & \mathrm{~A}_{33} & \mathrm{~B}_{13} & \mathrm{~B}_{23} & \mathrm{~B}_{33} \\
\mathrm{~B}_{11} & \mathrm{~B}_{12} & \mathrm{~B}_{13} & \mathrm{D}_{11} & \mathrm{D}_{12} & \mathrm{D}_{13} \\
\mathrm{~B}_{12} & \mathrm{~B}_{22} & \mathrm{~B}_{23} & \mathrm{D}_{12} & \mathrm{D}_{22} & \mathrm{D}_{23} \\
\mathrm{~B}_{13} & \mathrm{~B}_{23} & \mathrm{~B}_{33} & \mathrm{D}_{13} & \mathrm{D}_{23} & \mathrm{D}_{33}
\end{array}\right] \times\left[\begin{array}{c}
\varepsilon_{\mathrm{x}} \\
\varepsilon_{\mathrm{y}} \\
\gamma_{\mathrm{xy}} \\
-\kappa_{\mathrm{x}} \\
-\kappa_{\mathrm{y}} \\
-\kappa_{\mathrm{xy}}
\end{array}\right]
$$

Exact solutions are found by iteratively solving the transcendental eigenvalue problem in equation 3 until the material strength limits are reached. The basis of this method was first proposed by Wittrick and Williams [99-101]. 


$$
\mathbf{K}(\mathrm{Q}) \mathbf{D}=\mathbf{P}
$$

$$
\begin{aligned}
& \text { where, } \quad \mathbf{K}=\text { global stiffness matrix } \\
& \mathbf{Q}=\text { critical load factor } \\
& \mathbf{D}=\text { displacement vector } \\
& \mathbf{P}=\text { perturbation forces }
\end{aligned}
$$

The elements of $\mathbf{K}(\mathrm{Q})$ are transcendental functions of the eigenparameter Q, and its eigenvalues may be found by solving equation 4 .

$$
\mathbf{K}(\mathrm{Q}) \mathbf{D}=\mathbf{0}
$$

Then equation 5 is solved to give the number of eigenvalues $\mathrm{J}$ which are lower than a trial value $Q^{*}$ of $\mathrm{Q}$.

$$
\mathrm{J}\left(\mathrm{Q}^{*}\right)=\mathrm{J}_{0}\left(\mathrm{Q}^{*}\right)+\operatorname{sign}\left[\mathbf{K}\left(\mathrm{Q}^{*}\right)\right]
$$

The use of only free or clamped edges allows the critical load factor $Q$ to be found for first mode buckling problems such as for the composite steel-timber stiffened wall systems.

\subsection{FEM}

\subsubsection{Modelling technique}

Explicit analysis was conducted in the finite element software Abaqus [102]. Locally orientated orthotropic materials were defined for the OSB and MGP10 sawn cut radiata pine studs used for the panel and the stud stiffeners respectively. Each of the parts were made from an eightnode linear brick with reduced integration (C3D8R) to model them as three-dimensional elements. The steel PT rod was modelled in a similar but isotropic manner for the important addition of initial post-tensioning. The post-tensioning was achieved through applying a temperature change in the rod; the appropriate temperature change was set such that it induced the desired PT force. This was applied prior to the external axial loading stage. This method of simulating post-tensioning in Abaqus through temperature change has been successfully used in prior studies [103, 104]. As for the crucial load bearing steel SHS, material non-linearity was considered through plastic material behaviour and hardening despite only moderate displacements/deformations expected prior to glue delamination. This was to ensure that during the parametric study, where a range of configurations were simulated, if the yield limit was reached prior to glue delamination, that the appropriate behaviour would be adequately 
captured. This is particularly important for the steel SHS, as it is by far the stiffest member, thus primary loaded, as well as having notably large plastic region. When the material transitions from the elastic to plastic region in the FE analysis, convergence issues may arise due to multi-linear and exact non-linear material models being based directly off coupon experiments which for steel often includes a yield plateau prior to hardening. To help ensure that this issue was circumvented a bilinear material model was used; upon yielding the non-linear model immediately enters strain hardening. The bilinear model with isotropic hardening was deemed appropriate due to quasi-static analysis, non-cyclic loading, moderately limited amount deformation as well as the limiting strength of the connection to the panel.

Only the yield strength and tangent modulus are needed, where tangent modulus has been calculated using the true stress and true strain data of grade 450 steel [105]. However, since ANSYS was not utilized, the tangent modulus could not be used as the input for the bilinear model, rather the plastic strain was necessary and calculated by the difference in strain at ultimate load $\left(\varepsilon_{u}\right)$ to that at the elastic limit $\left(\varepsilon_{p}\right)$ as below given in literature [105]. Additionally, NLGEOM was turned on in the step definition to account for the inclusion of non-linear effects of any notable displacements for subsequent steps. Due to the integration of composite action in the PT-CST system, connection between components is critical to achieve accurate simulation. Therefore, experimental tests specifically on the connections were conducted to gather the required contact properties for the FE models, these will be further outlined.

\subsubsection{Material Properties}

The steel components were simply modelled with isotropic properties for young's modulus, poisson's ratio and density. This corresponded to values of $2.1 \mathrm{GPa}, 0.3$ and $7850 \mathrm{~kg} / \mathrm{m}^{3}$ respectively. The yield stresses were set to $450 \mathrm{MPa}$ for the SHS and $350 \mathrm{MPa}$ for all other steel components in accordance to manufacturers specifications. In contrast, orthotropic materials properties were required for the timber panel and stud stiffeners, the set of values used are displayed in Table 4. Tests in accordance to the Australian Standards [106-108] and from additional studies [109-113] were used to determine the constants for the timber studs and OSB panel.

Table 4. Elastic constants for orthotropic materials.

\begin{tabular}{cccccccccc}
\hline Element & $\begin{array}{c}\boldsymbol{E}_{\mathbf{1}} \\
(\mathbf{M P a})\end{array}$ & $\begin{array}{c}\boldsymbol{E}_{\mathbf{2}} \\
\mathbf{( M P a )}\end{array}$ & $\begin{array}{c}\boldsymbol{E}_{\mathbf{3}} \\
\mathbf{( M P a )}\end{array}$ & $\boldsymbol{v}_{\mathbf{1 2}}$ & $\boldsymbol{v}_{\mathbf{1 3}}$ & $\boldsymbol{v}_{\mathbf{2 3}}$ & $\begin{array}{c}\boldsymbol{G}_{\mathbf{1 2}} \\
\mathbf{( M P a})\end{array}$ & $\begin{array}{c}\boldsymbol{G}_{\mathbf{1 3}} \\
\mathbf{( M P a})\end{array}$ & $\begin{array}{c}\boldsymbol{G}_{\mathbf{2 3}} \\
(\mathbf{M P a})\end{array}$ \\
\hline $\begin{array}{c}\text { Stiffener } \\
(\mathrm{MGP} 10)\end{array}$ & 10,000 & 600 & 600 & 0.33 & 0.5 & 0.4 & 670 & 670 & 50
\end{tabular}


The timber stud stiffeners are sawn cut MGP10 radiata pine which have a parallel to the grain tensile and compressive strength limit of 7.7 MPa and 18 MPa respectively, along with a bending and bearing strength of $17 \mathrm{MPa}$ and $30 \mathrm{MPa}$. This in accordance to AS/NZS1720 and timber design guides $[114,115]$. The engineered timber panel has tensile, compressive and shear strength limits of $11.9 \mathrm{MPa}, 12.5 \mathrm{MPa}$ and 3.48 MPa respectively, and a bending and bearing strength of $20.3 \mathrm{MPa}$ and $16.9 \mathrm{MPa}$. This is in accordance to manufacturers specification, AS/NZS 2269.1 and AS/NZS 4063.1 [95, 116, 117].

\subsubsection{Connections}

Representative simulation of composite systems requires accurate modelling of the connection between components; thus, experimental testing focusing on the connections was conducted, these shown in Figure 10 . The connections involve both mechanical fasteners and glue; therefore, both features were considered, tested and modelled.

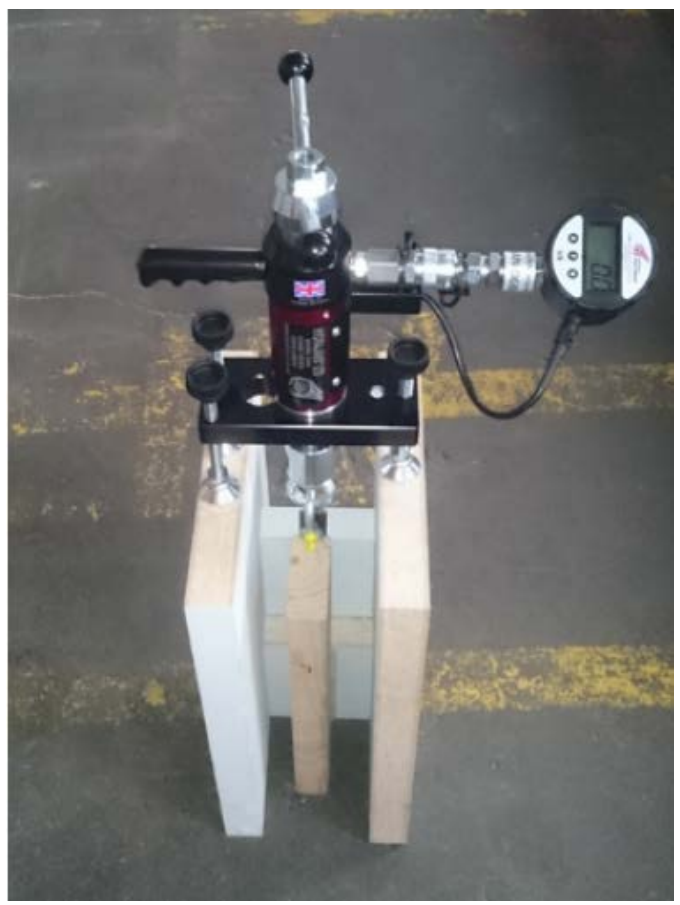

(a) 


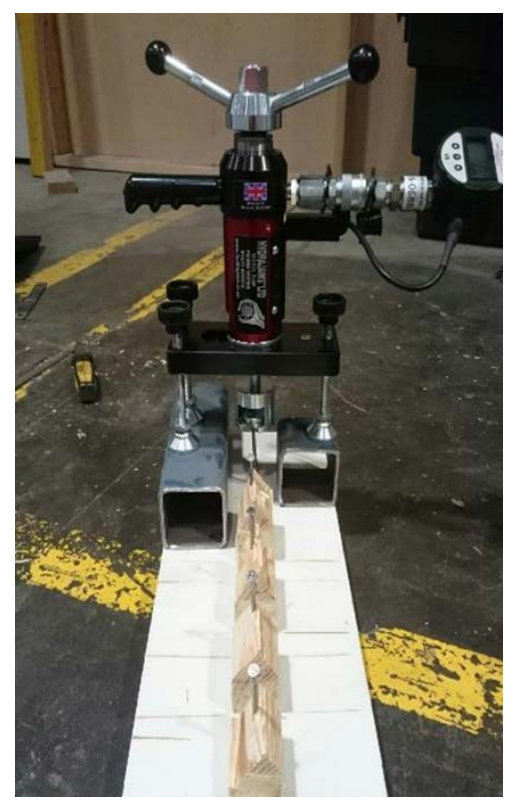

(c)

Figure 10. Connection testing, nail and adhesive: (a) Panel to stud shear strength connection; (b) Panel to SHS delamination and pull-off; (c) Panel to stud pull-out/off.

An embedded 2-node linear beam element (B31) was used to model the embedded nails. The nails interaction with the wood was determined from experimental results; these included a Young's modulus of $21.8 \mathrm{GPa}$, yield strength of $71 \mathrm{MPa}$ and a transverse shear stiffness of $181 \mathrm{MPa}$. The maximum allowable stress was in accordance to experimental testing and AS/NZS 1720.1 [118].

A rigid 1C PUR (one component polyurethane) was chosen as the adhesive due to its proven suitability for bonding timber components [119]. The cohesive traction-separation and damage evolution methods were used to model the adhesive action between the panel and stud stiffeners and panel and SHS through respective cohesive contact assignments and model definition. Tensile behaviour is captured in the normal direction whereas shear behaviour in the transverse direction; the traction-separation law as per equation 6.

$$
t=\left\{\begin{array}{l}
t_{n} \\
t_{s} \\
t_{t}
\end{array}\right\}=\left[\begin{array}{ccc}
K_{n} & 0 & 0 \\
0 & K_{s} & 0 \\
0 & 0 & K_{t}
\end{array}\right] \times\left\{\begin{array}{l}
\delta_{n} \\
\delta_{s} \\
\delta_{t}
\end{array}\right\}=K \delta_{n}
$$

Where, the subscript $\mathrm{n}=$ normal direction; subscript $\mathrm{t}$ and subscript $\mathrm{s}=$ transverse directions; $t=$ traction; $\delta=$ separation and $K=$ contact stiffness.

The damage initiation criterion as per equation 7 and damage evolution laws were used using normal and transverse contact stress and fracture energy. Once the contact stress limit is reached in either the normal or transverse directions damage will ensue in accordance to the 
damage evolution criteria using fracture energy; elastic behaviour occurs until peak traction where exponential decay then takes place as shown in Figure 11. The governing equation of this damage evolution is given in equation 8.

$$
\max \left\{\frac{t_{n}}{t_{n}^{0}} \frac{t_{s}}{t_{s}^{0}} \frac{t_{t}}{t_{t}^{0}}\right\}
$$

Where, $t_{n}^{0}=$ maximum contact stress in the normal direction and $t_{s}^{0}$ as well as $t_{t}^{0}=$ maximum contact stress in the transverse directions.

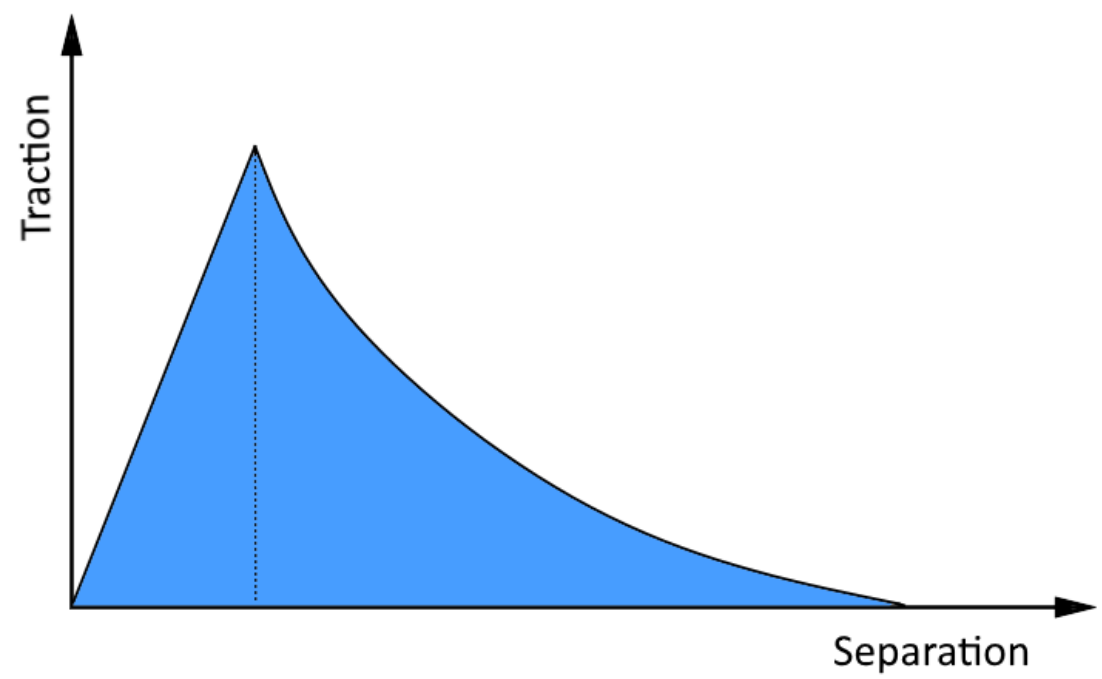

Figure 11. Traction-separation with exponential damage evolution.

$$
D=\int_{\delta_{m}^{0}}^{\delta_{m}^{f}} \frac{T_{e f f} d \delta}{G^{c}-G_{0}}
$$

Where the damage evolution is governed by: $T_{\text {eff }}=$ Effective post-peak traction (difference between post-peak and peak tractions); $G^{c}=$ fracture energy; $G_{0}=$ energy at damage initiation (elastic energy); $\delta_{m}^{f}=$ separation at fracture level and $\delta_{m}^{0}=$ separation at damage initiation (separation at peak traction).

These input parameters stem directly from the experimental tests as describe in detail in literature [102, 120,121]; the elasticity $E$ for the contact stiffness and the fracture energy $G_{f}$ used to model the glue via the traction-separation and damage evolution methods was obtained through scale testing on samples equivalent to the stiffened engineered timber wall panels. This 
was carried out through a Hydrajaws Model 2000 as shown previously in Figure 10; the method used matches that of previous studies [121-124]. The contact stiffness, damage initiation and fracture energy results are shown in Table 5.

Table 5. Experiential derived connection properties used in the FE models traction-separation method.

\begin{tabular}{|c|c|c|c|c|c|}
\hline & \multicolumn{2}{|c|}{ Contact Stiffness (MPa) } & \multicolumn{2}{|c|}{ Damage Initiation (MPa) } & \multirow[b]{2}{*}{$\begin{array}{c}\text { Fracture Energy } \\
\qquad\left(\mathrm{Nmm} / \mathrm{mm}^{2}\right)\end{array}$} \\
\hline & $\begin{array}{c}\text { Normal } \\
\text { (nn) }\end{array}$ & $\begin{array}{l}\text { Shear } \\
\text { (ss and tt) }\end{array}$ & $\begin{array}{c}\text { Normal } \\
\text { (nn) }\end{array}$ & $\begin{array}{l}\text { Shear } \\
\text { (ss and tt) }\end{array}$ & \\
\hline Panel to stud & 7.8 & 7.8 & 0.51 & 0.51 & 0.9 \\
\hline Panel to SHS & 52.2 & 52.2 & 1.71 & 1.71 & 5.1 \\
\hline
\end{tabular}

\section{Results and Discussion}

\subsection{Verification and Validation}

\subsubsection{Peak force}

As per the investigations method previously outlined, FEM models have been developed for a range of possible configurations. These include changing the thickness of the panel, height of the wall and number of adjacent stud stiffeners per standard $450 \mathrm{~mm}$ spacing. The capacities to the set of configurations was also predicted via analytical means as described in order to provide verification to the FEM. A summary of the verification is shown in Table 6. The significance and purpose of generating the summary verification table across the parameters is to provides confidence in the FE method since it will later be used to generate results to indicate the behavioural trend under all circumstances as later presented.

Table 6. Verification of results, FEM to analytical.

$$
P_{u} \text { - Ultimate Axial load (kN) }
$$

\begin{tabular}{ccccc}
\hline & $\begin{array}{c}\text { Configuration } \\
\text { (in accordance to standard configuration } \\
\text { with a PT of } 0 \mathrm{kN} \text { unless specified) }\end{array}$ & FEM & Analytical & $\begin{array}{c}\text { Discrepancy } \\
\text { (Analytical to FEM.) }\end{array}$ \\
\hline $\begin{array}{c}\text { Vary } \\
\text { thickness } \\
\text { Vary }\end{array}$ & $\mathrm{t}=20$ to $60 \mathrm{~mm}$ & 269.4 up to 379.7 & 296.3 up to 398.7 & From $10 \%$ to $5 \%$ \\
height & $\mathrm{h}=2.4 \mathrm{~m}$ to $3.6 \mathrm{~m}$ & 434.6 down to 256.2 & 467.2 down to 289.5 & From $7.5 \%$ to $13 \%$ \\
Vary & & & & From $9 \%$ to $2 \%$ \\
Studs & Single, Double, Triple & 303.2 up to 496.4 & 330.5 up to 506.3 & \\
\hline
\end{tabular}

The FSM idealises each component as thin shells rather than three dimensional elements; although the walls itself lends to this simplification, there is some impact on how representative the end pinned support conditions are, thus a potential reason for its overall conservativity. The 
best agreements between the FEM and analytical results were for walls with greater number of stiffeners and walls with thicker panels. Therefore, it can be said that in this application, engineered timber stiffened walls which have wider and thicker components both in terms of the panel and the stiffeners have their predicted composite capacity more closely matched by the two methods. This may be due to the differing failure modes, particularly, that of the steel as compared to timber. Building from the confidence gained of the FEM through verification, an experimental setup was configured, and an investigation program was designed. This was such as to safely test and robustly determine through experimental means the actual performance of the engineered timber composite walls under various key configurations. The gathered experimental results and behaviour were compared to the FEM simulations in order to validate them. Table 7 demonstrates the successful validation of the FEM which accurately predicts the ultimate load as found in the experiments. This is likely due to the critical failure being the connection between the panel and the stiffeners which is accurately modelled through cohesive traction-separation and damage evolution methods. However, some degree of underprediction always occurred, regardless of the level of post-tensioning. This is likely due to the reliance on capturing the exact behaviour of each component. This is particularly difficult for timber since it is a natural material and non-homogenous.

Table 7. Validation of results, experiment to FEM.

\begin{tabular}{cccc}
\cline { 2 - 3 } & \multicolumn{1}{c}{$\boldsymbol{P}_{\boldsymbol{u}}$ - Ultimate Axial load (kN) } & \\
\hline $\begin{array}{c}\text { Configuration } \\
\text { (In accordance to standard configuration } \\
\text { unless specified.) }\end{array}$ & FEM & Experiment & $\begin{array}{c}\text { Discrepancy } \\
\text { (FEM to experiment.) }\end{array}$ \\
\hline Single (3.2m height, PT0) & 303.2 & 316.5 & $-4.2 \%$ \\
Single (3.2m height, PT30) & 286.8 & $\overline{\mathrm{X}}=304.8, \sigma=2.2$ & $-5.9 \%$ \\
Single (3.2m height, PT45) & 278.5 & 300.9 & $-7.4 \%$ \\
Single (3.2m height, PT80) & 259.3 & 280.6 & $-7.6 \%$ \\
Single (4.0m height, PT30) & 249.9 & 253.8 & $-1.5 \%$
\end{tabular}

\subsubsection{Force-deflection behaviour}

Capturing the deflection behaviour under axial loading also provided an important means of validation of the FEM. It is particularly significant that these matched accurately since the panel component of these walls are easily classify as slender. This is due to its slenderness ratio, that is, it height divided by thickness $(\mathrm{H} / \mathrm{t})$ is 84 , being well over classic definitions of 30 and above [125]. Therefore, these walls are prone to global buckling. Because of this, stiffeners were incorporated into the design, however, buckling is still one of the principle mechanisms for failure prior to stiffener delamination as demonstrated by experimental and FEM results as 
per Figure 12a and 12b. Therefore, it is important to capture of the out-of-plane deflection accurately since serviceability limits states (SLS) are likely to govern. This behavioural capture was accomplished by the FEM as demonstrated in Figure 13. The observed softening behaviour that occurs after the serviceability range is caused by both geometric and material nonlinearity. Geometric nonlinearity is fundamentally present due to buckling as well as the slender walls loss of stability under eccentric loading, whereas material nonlinearity is due to the plastic nature of the steel, specifically the SHS.

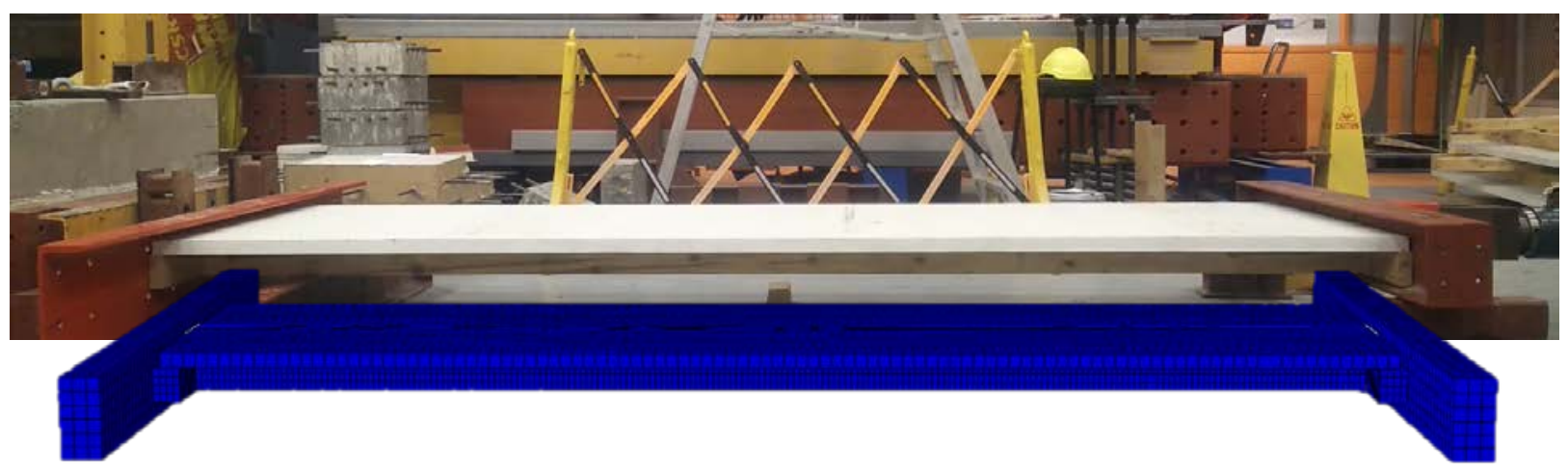

(a)

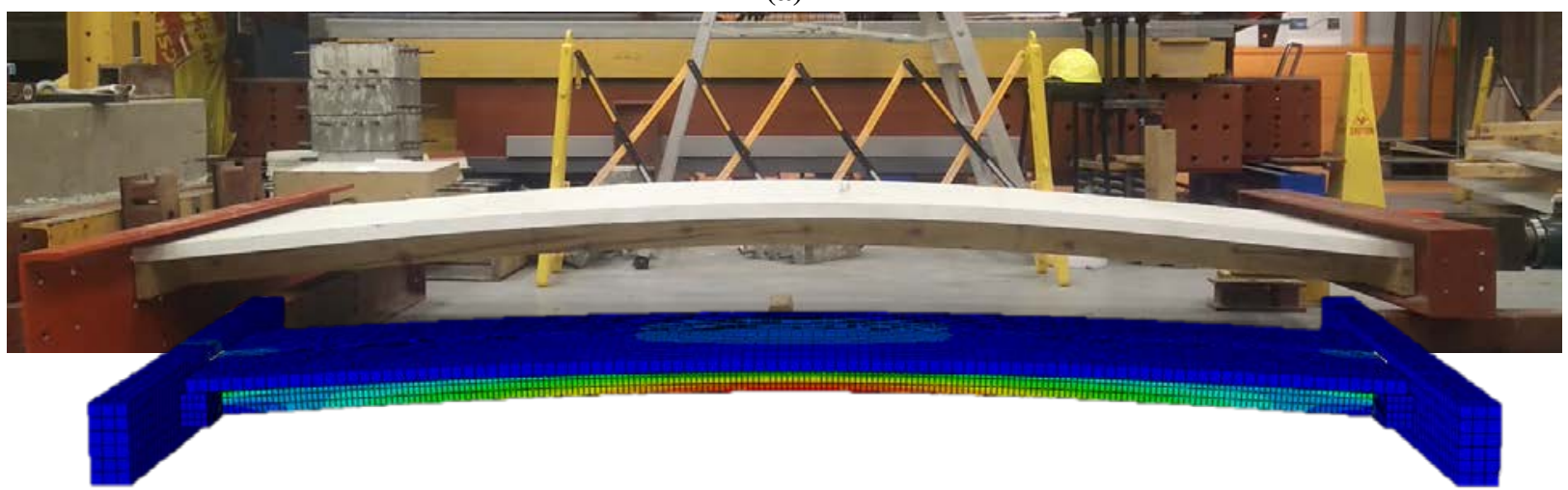

(b)

Figure 12. Experimental and FEM visualised: (a) Prior to post-tensioning and axial loading; (b) After loading prior to critical failure. 


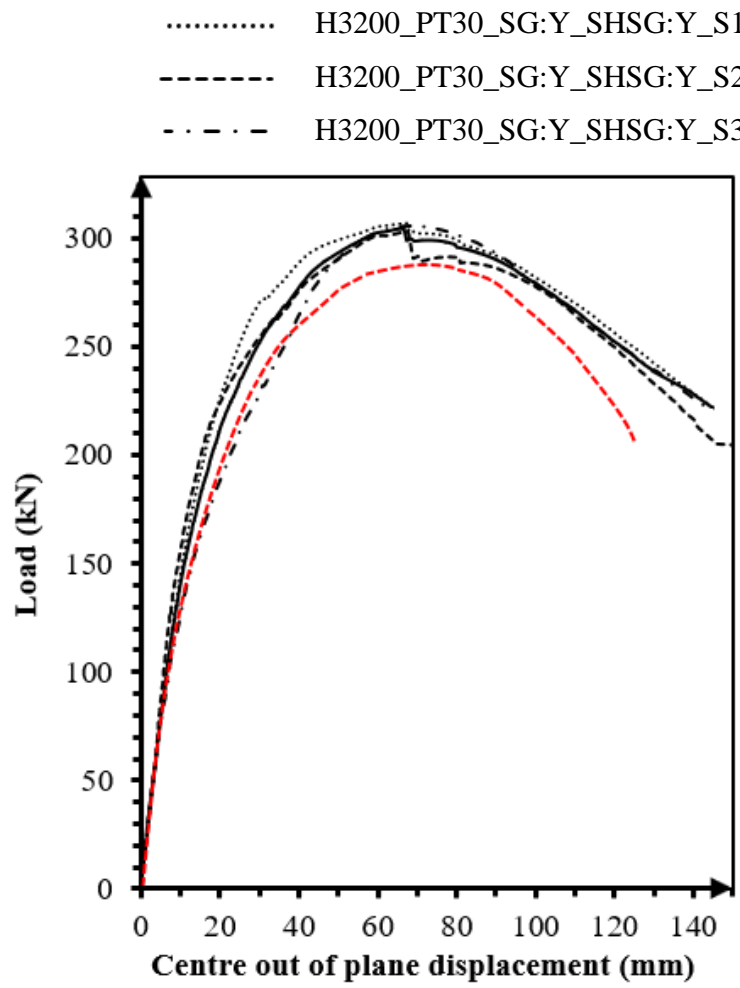

(a)
H3200_PT30_SG:Y_SHSG:Y_AVG

FEM_H3200_PT30_SG:Y_SHSG:Y

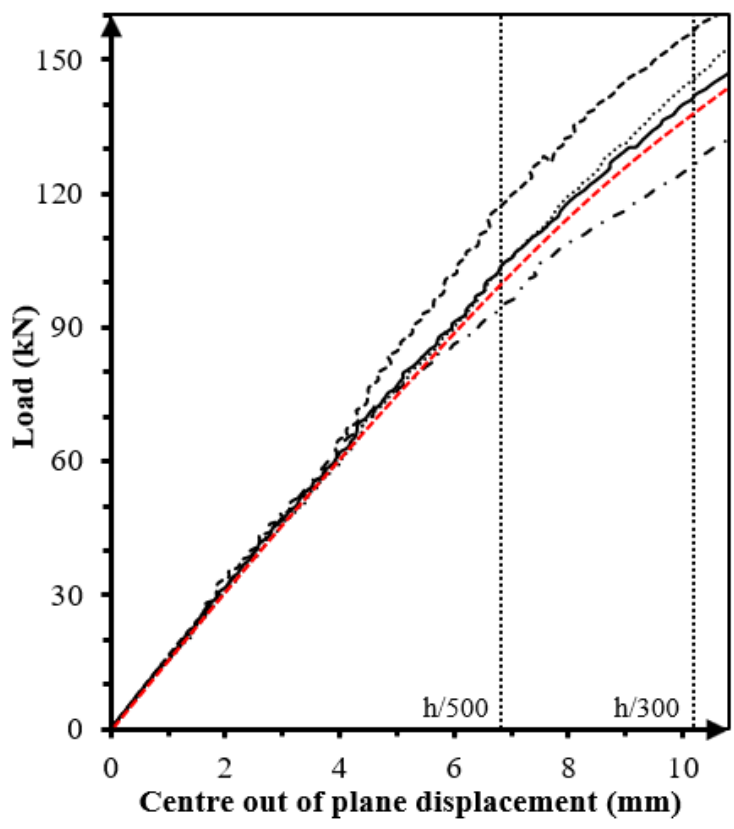

(b)

Figure 13. Force-deflection behaviour, experimental results as compared to FEM: (a) full behaviour with modes of failure numbered; (b) behaviour within serviceability range.

\subsection{Post-tensioning}

Once on-site, the prefabricated walls are lifted into place and post-tensioned to form the panel to panel connection prior to release and lifting of the next wall. In this intermediary state internal stresses are experienced in the wall even without the application of any gravity loading. Therefore, it is critical that the amount of PT applied at this state to be sufficient for the connection and hold-down but not such that the wall will bow or buckle.

The presented system is designed such that maximum specifiable post-tension force does not notably deflect the wall at all let alone approach serviceability deflection limits. This may initially seem unnecessarily conservative however it is imperative in order to alleviate the risk of snap through buckling and mitigate associated user discomfort and potential damage. This is particularly important when brittle claddings are used, since a strict h/500 SLS limit then applies. The potential of snap through buckling must be considered for all PT systems during the temporary state at installation prior to loading in the permanent state. Therefore, it is imperative that the location and amount force in the PT rod is not greater than that which would cause the housing SHS to buckle and hence deflect the wall. 
Experimentally, the post-tensioning was increased from $0 \mathrm{kN}$ up to $74.9 \mathrm{kN}$ by applying increasing amounts of torque to the coupling nuts and compared to the calculations derived from strain gauge readings. The mid-height deflection as per laser transducer did not read any significant extent of out-of-plane deflection during this stage, even for the maximum level of post-tensioning applied. Out-of-plane deflection was considered significant if it was close to the serviceability limits. In all instances initial PT resulting in out-of-plane deflection within 1 $\mathrm{mm}$, that is, within $1 / 10^{\text {th }}$ of the serviceability limit.

The FE models were analysed to determine the pattern and extent of distribution of stress throughout the wall caused by the PT. This is shown in Figure 14 from (a) to (d). The initial application of PT more greatly effects the ends of the wall at the centre, as seen in (b), this is where the SHS is located. When the PT force is increased as per (c), the stress distributes along the height of the panel, but only in the central region. This indicates that the effects of posttensioning are rather localised to the region it is applied to due to the shear lag effect and the disproportionally high stiffness of the post-tensioned SHS as compared to the timber panel. Further increases to the level of post-tensioning continues this behaviour as shown by (d). Once a nominal amount of PT is applied, then axial loading of the wall commences which replicates the transition from intermediary state during assembly of a given level to the permanent state where the floor levels above are installed and occupied.

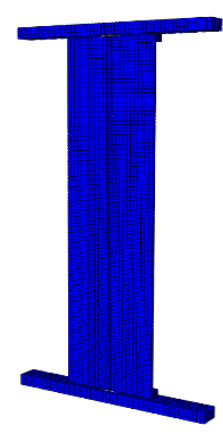

$\mathrm{PT}=0 \mathrm{kN}$

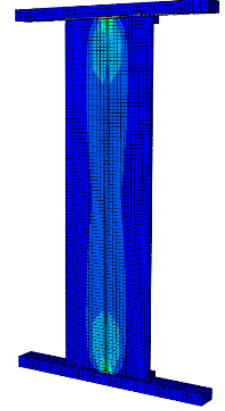

$\mathrm{PT}=20 \mathrm{kN}$

(b)

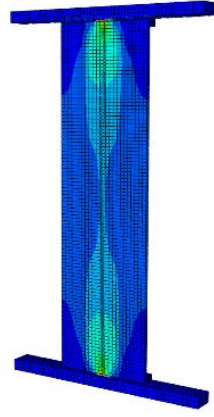

$\mathrm{PT}=40 \mathrm{kN}$

(c)

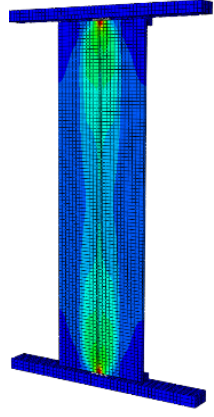

PT $=80 \mathrm{kN}$

(d)

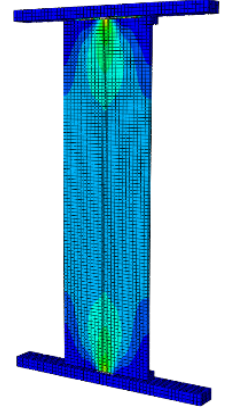

Disp. $=5 \mathrm{~mm}$

(e)

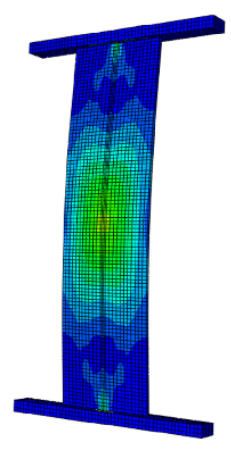

Disp. $=60 \mathrm{~mm}$

(f)

Figure 14. FEM stress distribution throughout the post-tensioning phase and then under the axial loading.

Figure 14 (e) and (f) are of the wall after PT has been applied and axial loading is conducted such that mid-height out-of-plane displacement is $5 \mathrm{~mm}$ and $60 \mathrm{~mm}$ respectively. As seen in (e) the axial force reduces the peak distributed stresses caused by the PT, especially at the ends, but increases the overall bending stress at mid-height due to the onset of bow. Eccentricity causes this bow to develop through associated P- $\Delta$ effects as shown in (f), the follow-on effect 
of this is that all the initial PT force is now lost. The inherit loading eccentricity prior to deflection or bowing occurring is $16.61 \mathrm{~mm}$ towards the stiffener side from the centre of gravity as indicated in Figure 15. As the load increases, a bow develops towards the panel side of the wall. Significant P- $\Delta$ effects cause further bow as the load continues up to the peak load; at this stage a maximum out-of-plane displacement of approximately $60 \mathrm{~mm}$ is experienced.

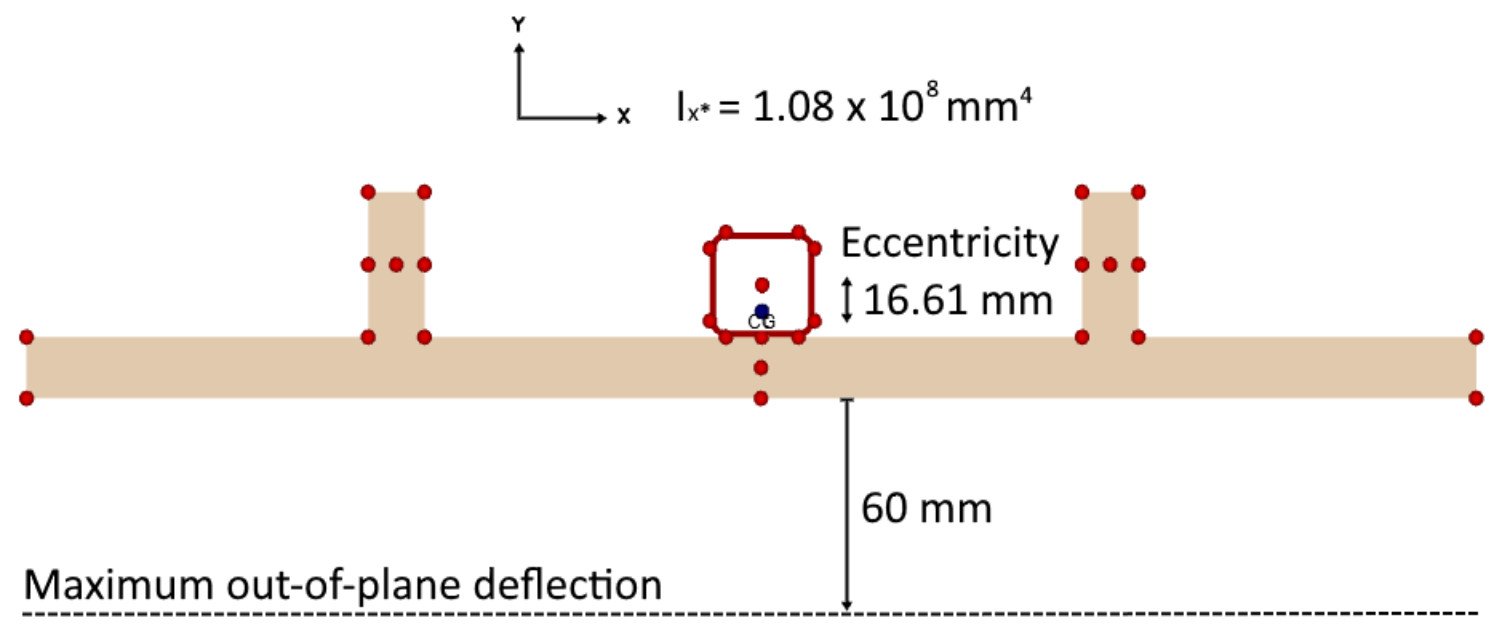

Figure 15. Contributing to $P-\Delta$ effects of eccentricity from the centre of gravity and bow direction and magnitude.

\subsection{Design curves}

The analytically and experimentally verified and validated FEM models have been used on the proposed CST system over an array of 240 different geometrical wall configurations. The geometrical parameters investigated included the thickness of the panel, number of stiffeners and height of the wall. The comprehensive set of results were used to generate simple yet versatile design curves for various structural scenarios. The corresponding design curve is presented in Figure 16 which can be used to determine $\boldsymbol{P}_{\boldsymbol{u}, \mathbf{0}}$, that is the ultimate load capacity per metre of wall at $0 \mathrm{kN}$ of initial PT force for any respective PT-CST wall configuration. Or alternatively it can be used to find suitable configurations for a required capacity. Finally, the flexural rigidity of each wall configuration is denoted by the vertical EI axis which maps the walls capacity to panel thickness (between $20 \mathrm{~mm}$ and $60 \mathrm{~mm}$ ), and number of adjacent stud stiffeners (single, double, triple), for a range of wall heights between $2.4 \mathrm{~m}$ and $3.6 \mathrm{~m}$. 


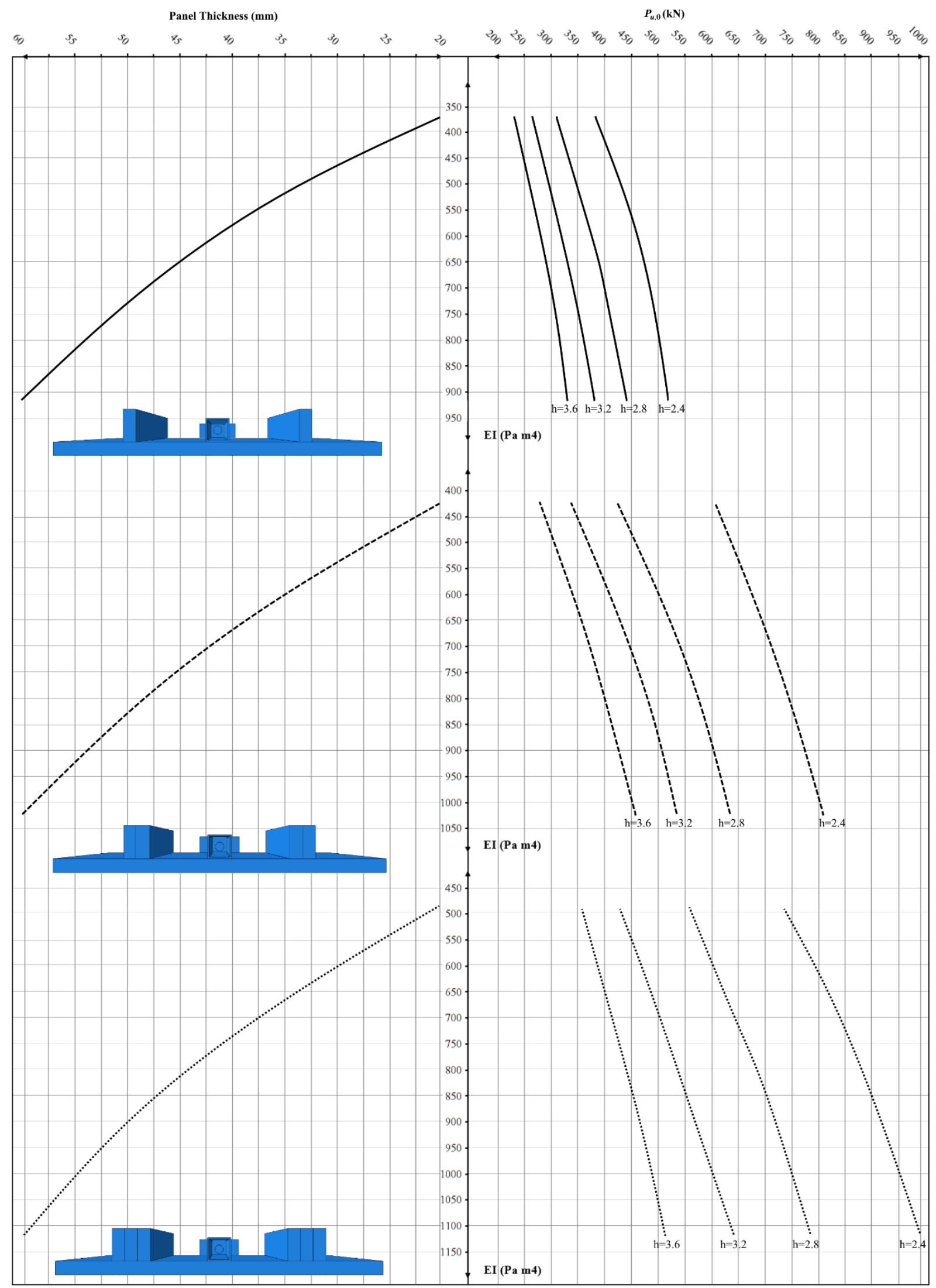

Single stud stiffener

Double stud stiffener

Triple stud stiffener

*h = Wall hieght (m) **MGP10 Radiata Pine $90 \times 35 \mathrm{~mm}$ studs at 450 cts., OSB4 Panel, Steel grade $300 \mathrm{MPa}, 65 \times 65 \times 4 \mathrm{~mm}$ SHS at 900 cts., Rod $\varnothing 21.7 \mathrm{~mm}, 1 \mathrm{C}$ Polyurathane, Nailed at $400 \mathrm{cts}$.

Figure 16. Design Curves to determine $\boldsymbol{P}_{\boldsymbol{u}, \mathbf{0}}$ and/or configuration. That is the ultimate load capacity per $\mathrm{m}$ of wall at $0 \mathrm{kN}$ of PT force for the respective PT-CST stiffened wall configuration/s and their flexural stiffness EI. 
As can be seen in Figure 16 there are three sets of graphs corresponding to single, double and triple stud scenarios which have separated in, so as to distinctly differentiate between them. The curves are in vertical alignment with respect to the parameters of panel thickness as well as $\boldsymbol{P}_{\boldsymbol{u}, \mathbf{0}}$. This allows for efficient identification and comparison of applicable solutions to a given problem. It is shown in Figure 16, that for any given configuration, increasing the maximum applied gravity load requires either the panel thickness to be increased, the number of adjacent stud stiffeners to increase or the wall height to decrease. Notably decreasing the height has the greatest effect on improved capacity however to meet a client's specification of taller walls, adaption of the structural configuration through increased panel thickness and greater number of adjacent stud stiffeners as presented is to be appropriately specified to achieve required capacities.

\section{$4.4 \phi_{k}$ - Strength reduction factor for $k \mathrm{kN}$ of initial PT force}

11 A strength reduction factor $\boldsymbol{\phi}_{\boldsymbol{k}}$ is proposed and studied due to the effects of initial posttensioning on capacity. Post-tensioning a wall on the same side as the neutral axis as the location of load may remove the risk of snap through buckling but as found, reduces its capacity. This can be easily explained through thinking of the post-tensioning as a sort of preload which reduces the amount of additional load which can then be applied. It can be mistaken that the external load applied will simply exactly replace the post-tensioning force since the post-tensioning will be lost as compression and buckling ensues. This outlook would lead one to believe that the post-tensioning will not affect the capacity of the system which is incorrect. This is because the post-tensioning location is offset from the neutral axis and causes a P- $\Delta$ effect similar to that of an initial imperfection, such that when the external load is applied deflection ensues. Therefore, in this configuration, the eccentricity of the PT causes a reduction of strength however at the same token safeguards against snap-through buckling. From the experimental results and the FEM modelling, it was found that there is essentially a linear decrease in capacity with the increase of initial-post-tensioning force. The results of which are presented below in Figure 17 which shows the experimental results as compared to the more conservative model based on FEM. 


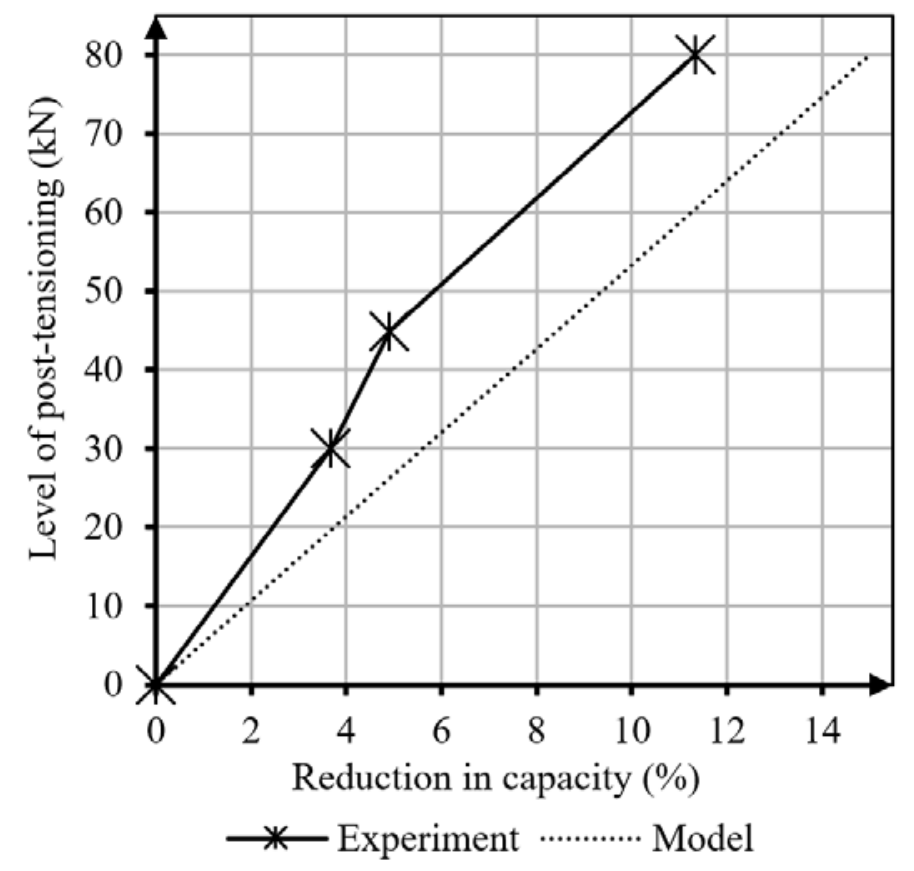

Figure 17. Various levels of post-tensioning and corresponding reduction in capacity.

It is important to note that reduction in capacity presented prior is specific to various levels of post-tensioning for the typical configuration which was tested. To generalise the result such that it can be applied to alternative configurations with various parametric changes a complementing parameter must be developed. This complementing parameter must be based on the critical factors influencing the strength loss specifically due to PT. In this case $\boldsymbol{\phi}_{\boldsymbol{k}}$, the strength reduction factor for $\mathrm{kN}$ of initial PT, will be made dependent on $\boldsymbol{\phi}_{\mathbf{8 0}}$, a configuration specific factor at the maximum PT force of $80 \mathrm{kN}$.

$$
\phi_{k}=1-\frac{k}{80} \times\left(1-\phi_{80}\right)
$$

where, $\quad \phi_{k}=$ Strength reduction factor for $\mathrm{k} \mathrm{kN}$ of initial PT force

$\phi_{80}=$ Configuration specific strength reduction factor after maximum allowable amount of initial PT force, $80 \mathrm{kN}$

$k$ = Applied PT force

\section{$4.5 \phi_{80}$-Configuration specific strength reduction factor due to PT}

In addition to all the geometrical configurations and corresponding FEM models used to generate the design curve, various levels of PT was simulated for these walls. This considerably multiplied the total number of run simulations and computational time. However, it has allowed a configuration specific strength reduction factor $\boldsymbol{\phi}_{\mathbf{8 0}}$ to been developed in order to be used in conjunction with the design curves to address the effects of PT force on axial capacity. Critical leading factors have been identified and investigated for the scope of structural configurations 
41 relevant to this system. The results have supported the hypothesis that regardless of the height, number of stiffeners and thickness of the panel, post-tensioning will always reduce the capacity when by design it is inherently applied on the side of the neutral axis as the load. It was found that the extent of capacity reduction due to post-tensioning is not solely governed by the level of post-tensioning itself, but also the specific configuration of the engineered timber wall. In brief, the wall height and the flexural rigidity in terms of number stiffeners and thickness of the panel governed this behaviour and thus formed the basis for the reduction factor due to post-tensioning.

\subsection{1 $\phi_{80}$ chart}

50 The configuration specific strength reduction factors after the maximum allowable amount of 51 initial PT force of $80 \mathrm{kN}$ are presented in Figure 18. The behaviour is demonstrative of the 52 effects of each prior outlined leading factor to the capacity of the post-tensioned stiffened engineered timber composite wall systems. The $\boldsymbol{\phi}_{\mathbf{8 0}}$ factors given here can be used in connection with Equation 9 in order to determine $\boldsymbol{\phi}_{\boldsymbol{k}}$ the strength reduction factor at a nominal $\mathrm{k} k N$ of initial PT force.

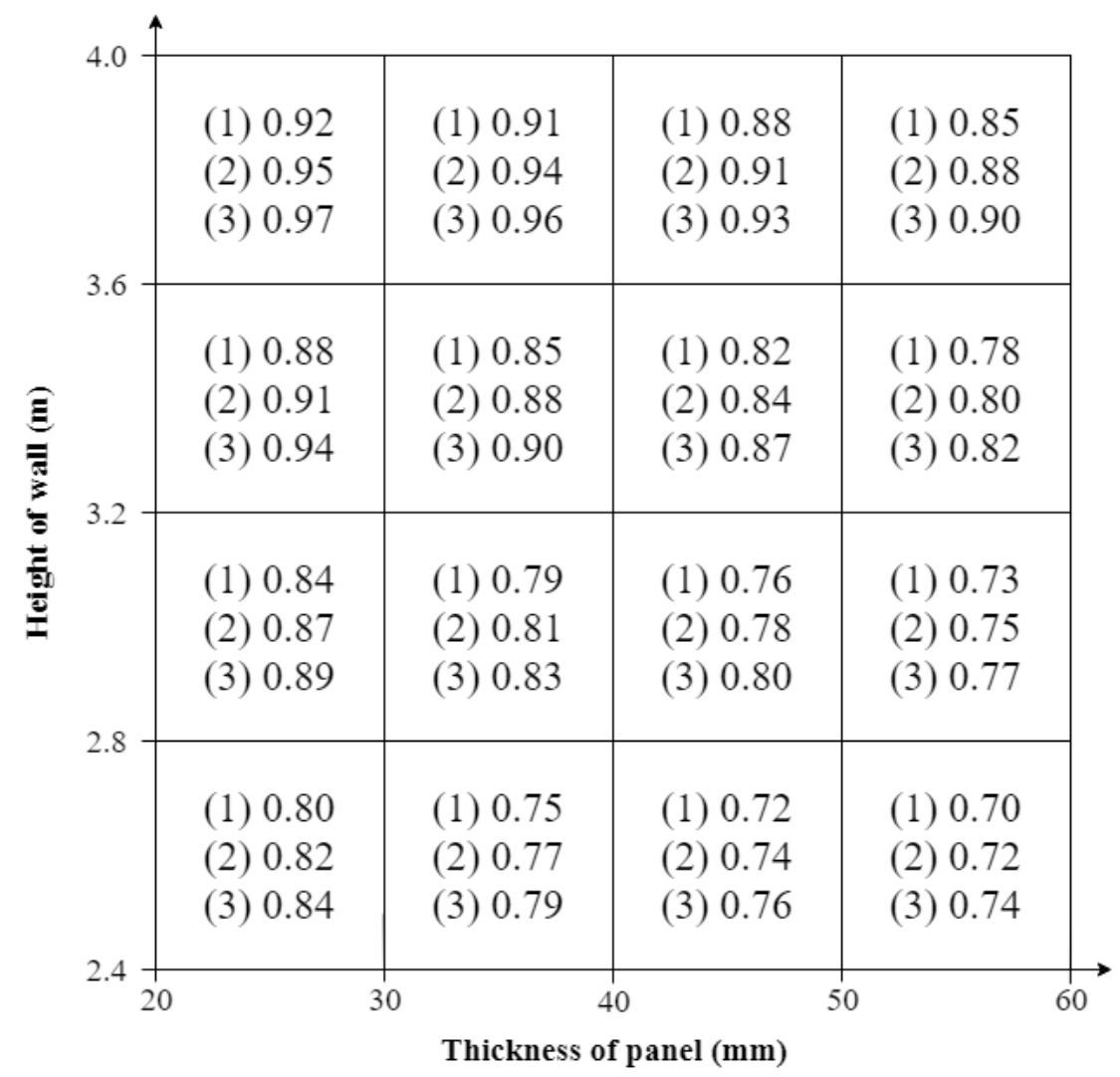

(1) One, (2) Two, (3) Three adjacent stud stiffeners

Figure 18. Strength reduction factor $\boldsymbol{\phi}_{\mathbf{8 0}}$ chart. Determines the maximum reduction factor due to post-tensioning under various configurations. 
It has been found that the thickness of the panel component plays a direct and important role in altering the extent of capacity reduction due to post-tensioning. The reason for this is that it shifts the location of the neutral axis and thus for a given force alters the effects of posttensioning and load on the system. That is for thicker engineered timber panels the neutral axis moves away from the location of post-tensioning and thus a greater level of capacity reduction is observed and vice versa. This is consistent with the strength reduction factor chart as shown previously in Figure 18.

\subsubsection{Number of adjacent stiffeners}

Increasing the number of adjacent stud stiffeners alters the location of the neutral axis such that the eccentricity of both the load and the post-tensioning reduces. In effect, this decreases the amount of capacity reduction due to post-tensioning. This is in contrast with increasing the thickness of the panel which increases capacity reduction. Importantly, it does this while increasing the global stiffness of the wall. That is, varying the number of studs clearly and strongly varies the peak capacity. Interestingly, with respect to this capacity, the associated reduction due to PT did not vary significantly in magnitude as compared to the results of varying the panel thickness. This is primarily due to the centroidal location of the studs not changing, as the number of adjacent studs is increased. Whereas for the panel, as the thickness changes so does its centroidal location. Further to this, the stud's centroid is close to that of the SHS and therefore the location of post-tensioning. Whereas for the panel, its centroidal location is notably offset from the location of post-tensioning and therefore sensitive to it. Table 8 summarises this information, positive values indicate that the PT tends to cause a bending moment in the direction away from the buckling direction and thus acts to prevent it. Likewise, the negative values indicate that it is acting in the direction of buckling and thus contributing to it.

Table 8. Centroidal location under stud and panel variations.

\begin{tabular}{cc}
\hline $\begin{array}{c}\text { Number of adjacent } \\
\text { studs }\end{array}$ & $\begin{array}{c}\text { Distance of elements } \\
\text { centroid to location of } \\
\text { PT (mm) }\end{array}$ \\
\hline 1 & +12.5 \\
2 & +12.5 \\
3 & +12.5 \\
\hline
\end{tabular}

\begin{tabular}{cc}
\hline $\begin{array}{c}\text { Thickness of panel } \\
(\mathbf{m m})\end{array}$ & $\begin{array}{c}\text { Distance of elements } \\
\text { centroid to location of } \\
\text { PT (mm) }\end{array}$ \\
\hline 20 & -42.5 \\
40 & -52.5 \\
60 & -62.5 \\
\hline
\end{tabular}




\subsubsection{Height of the wall}

83 Finally, Figure 18 results suggest that the height of the wall itself has a leading effect on the level of capacity reduction due to post-tensioning. Having a greater height of wall in its own right reduces the load bearing capacity due to increasing the walls susceptibility to buckling. This is particularly the case for walls made from timber and more so for engineered timber stiffened walls which are slender. The amount of extra reduction of capacity because of the inclusion of post-tensioning in taller walls was found not to be as large as that for shorter walls. This is crucially because in taller walls under axial loading, the post-tensioning force is lost quicker than for shorter walls. That is, for taller walls at a given level of loading, a greater outof-plane deflection is present than for shorter walls. This is particularly seen in the early stages or lower levels of loading since taller walls deflect more which causes the tension in the rod to diminish at a faster rate than for shorter walls. This differing rate of post-tension force loss is key to the effects of post-tensioning with height on the peak capacity. In fact, the experimental results also show that this is a rather significant phenomenon which is exacerbated by the fact that taller walls are also more prone to early stage out-of-plane deflection due to increased manufacturing and material imperfections. This is also supported and heightened by the fact that there is a large sensitivity within this system, even at $80 \mathrm{kN}$ of post-tensioning, the steel rod will only axially shorten by $3.5 \mathrm{~mm}$, and a more typical scenario of $30 \mathrm{kN}$ post-tensioning will only cause the steel rod to axially shorted by $1.3 \mathrm{~mm}$. Therefore, it is evident that the early level of out-of-plane displacement will play a very strong role in the initial rate of reduction of post-tensioning force and thus its potential effects in reducing the peak capacity of the system.

\subsection{Proposed design procedure}

The proposed design procedure is based on the design curves presented which were based on experimental, analytical and FEM results. This procedure facilitates an efficient structural design process and configuration specification for PT-CST wall systems. It takes the form of a robust set of design curves for ultimate capacity at $0 \mathrm{kN}$ post-tensioning as per Figure 16, in addition to an initial PT specific strength reduction factor due to a nominal level of posttensioning for any specific structural configuration as per Figure 18. This is to be used in conjunction with the simple design equations Equation 9 and Equation 10, with the proposed procedure elaborated as follows.

$$
\begin{aligned}
& \qquad \phi_{k}=1-\frac{k}{80} \times\left(1-\phi_{80}\right) \\
& \text { where, } \phi_{80}=\text { Strength reduction factor at } 80 \mathrm{kN} \text { of initial PT force }
\end{aligned}
$$




$$
P_{u, k}=P_{u, 0} \times \phi_{k}
$$

where, $\quad P=$ Load $(\mathrm{kN})$

$u=$ Ultimate

$k=$ Applied initial PT force $(\mathrm{kN})$

thus, $\quad P_{u, k}=$ Ultimate Load after $\mathrm{k} \mathrm{kN}$ of initial PT force

and $P_{u, 0}=$ Ultimate Load after $0 \mathrm{kN}$ of initial PT force

$$
\begin{aligned}
\text { Additionally, } & \phi=\text { Strength reduction factor } \\
\text { so } & \phi_{k}=\text { Strength reduction factor after } \mathrm{k} \mathrm{kN} \text { of initial PT force }
\end{aligned}
$$

113 If a desired configuration is known,

114

115

116 (that is in terms of the wall height, engineered timber panel thickness, number of stud stiffeners and amount of initial post-tensioning)

then:

(a simple a four-step process is as follows)

1. Determine $P_{u, 0}$ from the design curve as per Figure 16

2. Find $\phi_{80}$ from the reduction factor chart in Figure 18

3. Use this to find $\phi_{k}$ from Equation 9

4. Multiply $P_{u, 0}$ and $\phi_{k}$ to get $P_{u, k}$ as per Equation 10

Else if, a desired configuration is unknown, then:

1. Establish $P_{u, k}$ required

2. Divide $P_{u, k}$ by 0.70 and assume as $P_{u, 0}$ (worst case scenario of maximum strength reduction)

3. Trace $P_{u, k}$ vertically downwards on design curve as per Figure $\mathbf{1 6}$ and select all intersecting number of studs and height options applicable

4. For each, trace across to find the corresponding panel thickness required for each satisfactory configuration

5. Use the strength reduction factor chart in Figure $\mathbf{1 8}$ to determine $\phi_{80}$ for each option

6. Use Equation 9 to find $\phi_{k}$ for each satisfactory configuration

7. Multiply assumed $P_{u, 0}$ by $\phi_{k}$ to get $P_{u, k}$ for each option (each will be equal or greater than that required)

8. Refine if/as necessary

9. Assess each satisfactory configuration option 

such as suitability for project, material availability, preference in manufacturing methods and cost.

In summary, for a set panel thickness, the amount of number of adjacent studs and posttensioning required for a given load can be easily determined. This allows for quick identification of the most material efficient PT-CST wall solutions to be chosen for further consideration. In fact, the chosen design may itself taper off the higher the building goes whilst also maintaining interconnectivity and ease and consistency of manufacture as the load requirement reduces. In a similar way, a required load capacity can easily be checked against the all possible configurations to find which is most suitable along with the corresponding level of initial post-tensioning. This may prove especially useful in the early stages of a project when identifying structural solution options and establishment of feasibility is of concern. Moreover, the simplification of optimised design and showcasing of material efficient performance may promote the adoption of post-tensioned composite steel-timber stiffened wall systems.

\section{Conclusion}

150 This study has introduced the design of Post-Tensioned Composite Steel-Timber (PT-CST) stiffened wall systems which offer a material efficient solution for mid-rise timber-based buildings. The generated outcomes are of particular value during initial feasibility analysis where the capabilities of potential systems are evaluated. A collection of versatile design curves together with a strength reduction factor due to PT has been proposed under a comprehensive array of parametric changes. These include the amount of post-tensioning force, the thickness of the panel, number of adjacent stud stiffeners, height of the wall and applied load. An exhaustive set of incremental results supported by analytical, experimental and finite elemental methods has enabled highly versatile yet simple design curves to be developed. A design procedure has been proposed which makes use of these design curves along with a configuration specific strength reduction factor due to any nominal level of post-tensioning. This allows rapid assessment of PT-CST stiffened walls. For a desired axial load capacity and PT level, the optimal system configurations can now be quickly found. Likewise, for a chosen configuration and the allowable axial load and PT is given.

Acknowledgements - The authors would like to acknowledge the generous support provided by The 165 University of Melbourne, Prof. Priyan Mendis, Dr Shanaka Kristombu Baduge, the Centre for 166 Advanced Manufacturing of Prefabricated Housing (CAMP.H) and the Australian Research Council 167 (Project ID: IC150100023). 
169 1. Tykkä, S., et al., Development of timber framed firms in the construction sector-Is EU policy one source of

their innovation? Forest Policy and Economics, 2010. 12(3): p. 199-206.

2. Lawson, R.M., R.G. Ogden, and R. Bergin, Application of modular construction in high-rise buildings. Journal of architectural engineering, 2011. 18(2): p. 148-154.

3. Orlowski, K., K. Shanaka, and P. Mendis, Manufacturing, Modeling, Implementation and Evaluation of a Weatherproof Seal for Prefabricated Construction. Buildings, 2018. 8(9 - Article 120).

4. Zumbrunnen, P. and J. Fovargue. Mid-rise CLT buildings-The UK's experience and potential for Aus and NZ. in World Conference on Timber Engineering WCTE. 2012.

5. $\quad$ Orlowski, K., K. Shanaka, and P. Mendis, Design and Development of Weatherproof Seals for Prefabricated Construction: A Methodological Approach. Buildings, 2018. 8(9 - Article 117).

6. $\quad$ Energy, D.o.t.E.a., Australia's Guide to Environmentally Sustainable Homes. YourHome, 2017.

7. Keyworth, B., Timber Frame Construction. Journal of the Royal Society of Health, 1984. 104(4): p. 135-137.

8. FWPA, Timber-framed Construction for Townhouse Buildings Class 1a. Technical Design Guide issued by Forest and Wood Products Australia. Design and construction guide for BCA compliant sound and fire-rated construction., 2012.

9. FWPA, Timber-framed Construction for Multi residential Buildings Class 2 \& 3. Technical Design Guide issued by Forest and Wood Products Australia. Design and construction guide for BCA compliant sound and fire-rated construction, 2015.

10. Kremer, P.D., Design for Mass Customised Manufacturing and Assembly (DfMCMA): A Framework for Capturing Off-site and On-site Efficiencies in Mass Timber Construction. Mass Timber Construction Journal, 2018. 1(1): p. 9-13.

11. Livingstone, A., et al. The Case for Mass Customisation of Structural Timber Design. in Structures Congress 2015. 2015.

12. Yuan, Z., C. Sun, and Y. Wang, Design for Manufacture and Assembly-oriented parametric design of prefabricated buildings. Automation in Construction, 2018. 88: p. 13-22.

13. Gao, S., S.P. Low, and K. Nair, Design for manufacturing and assembly (DfMA): a preliminary study of factors influencing its adoption in Singapore. Architectural Engineering and Design Management, 2018. 14(6): p. 440-456.

14. Duncheva, T. and F.F. Bradley, Multifaceted Productivity Comparison of Off-Site Timber Manufacturing Strategies in Mainland Europe and the United Kingdom. Journal of Construction Engineering and Management, 2019. 145(8): p. 04019043.

15. Bylund, D. Learn-by-making and its role in architectural education-Examples from Sweden and Australia. in 3rd International Conference on Structures and Architecture (ICSA 2016). 2016.

16. Schuler, A., C. Adair, and E. Elias, Engineered lumber products: Taking their place in the global market. Journal of Forestry, 2001. 99(12): p. 28-35.

17. Orlowski, K., et al., Structural behaviour of prefabricated stressed-skin engineered timber composite flooring systems. Structures, 2019. 22: p. 230-244.

18. IBC, I., International building code. International Code Council, Inc.(formerly BOCA, ICBO and SBCCI), 2006. 4051: p. 60478-5795.

19. Orlowski, K.A., Synchronization of Sustainable Development with Land Development, in Sustainable Development Research in the Asia-Pacific Region: Education, Cities, Infrastructure and Buildings, W. Leal Filho, J. Rogers, and U. Iyer-Raniga, Editors. 2018, Springer International Publishing: Cham. p. 449-463.

20. Bianconi, F., M. Filippucci, and A. Buffi, Automated design and modeling for mass-customized housing. A web-based design space catalog for timber structures. Automation in Construction, 2019. 103: p. 13-25.

21. Poirier, E., et al. Design and construction of a 53-meter-tall timber building at the university of British Columbia. in Proceedings of the World Conference on Timber Engineering, Vienna, Austria. 2016.

22. Van de Kuilen, J., et al., Very tall wooden buildings with cross laminated timber. Procedia Engineering, 2011. 14: p. 1621-1628.

23. Buchanan, A., et al. Non-conventional multi-storey timber buildings using post-tensioning. in 11th international conference on non-conventional materials and technologies, Bath, UK. 2009.

24. Mahapatra, K. and L. Gustavsson, Multi-storey timber buildings: breaking industry path dependency. Building Research \& Information, 2008. 36(6): p. 638-648.

25. Palermo, A., et al., Seismic design of multi-storey buildings using laminated veneer lumber (LVL). 2005.

26. Palermo, A., et al. From theory to practice: Design, analysis and construction of dissipative timber rocking post-tensioning wall system for Carterton Events Centre, New Zealand. in Proceedings of the 15th World Conference on Earthquake Engineering, Lisbon, Portugal. 2012.

27. Sarti, F., Seismic design of low-damage post-tensioned timber wall systems, in Civil Engineering. 2015, University of Canterbury: New Zealand.

28. Sarti, F., A. Palermo, and S. Pampanin, Fuse-type external replaceable dissipaters: experimental program and numerical modeling. Journal of Structural Engineering, 2016. 142(12): p. 04016134. 
29. Sarti, F., et al. Evaluation of the seismic performance factors of post-tensioned timber wall systems. in European Conference on Earthquake Engineering and Seismology, Istanbul, Turkey. 2014.

30. Akbas, T., et al., Analytical and experimental lateral-load response of self-centering posttensioned CLT walls. Journal of Structural Engineering, 2017. 143(6): p. 04017019. Ganey, R.S., Seismic design and testing of rocking cross laminated timber walls. 2015.

32. Wiebe, L. and C. Christopoulos, Mitigation of higher mode effects in base-rocking systems by using multiple rocking sections. Journal of Earthquake Engineering, 2009. 13(S1): p. 83-108.

33. Restrepo, J.I. and A. Rahman, Seismic performance of self-centering structural walls incorporating energy dissipators. Journal of Structural Engineering, 2007. 133(11): p. 1560-1570.

34. Chancellor, N., et al., Self-centering seismic lateral force resisting systems: High performance structures for the city of tomorrow. Buildings, 2014. 4(3): p. 520-548.

35. Nakaki, S.D., An overview of the PRESSS five-story precast test building. PCI journal, 1999. 44(2): p. 26-29.

36. Ganey, R., et al., Experimental investigation of self-centering cross-laminated timber walls. Journal of Structural Engineering, 2017. 143(10): p. 04017135.

37. Holden, T., et al., NMIT Arts \& Media Building-Innovative structural design of a three storey post-tensioned timber building. Case Studies in Structural Engineering, 2016. 6: p. 76-83.

38. Nguyen, A.C., P. Vestartas, and Y. Weinand, Design framework for the structural analysis of free-form timber plate structures using wood-wood connections. Automation in Construction, 2019. 107: p. 102948.

39. XLam, XLam Design Guide Office 8, 4-10 Bank Place, Melbourne, Australia. XLam Australia Pty Ltd., 2018.

40. Devereux, C., et al., NMIT arts \& media building-damage mitigation using post-tensioned timber walls. 2011.

41. $\quad$ Sarti, F., Simplified design methods for post tensioned timber buildings. 2011.

42. Dowden, D.M. and M. Bruneau, Quasi-static cyclic testing and analytical investigation of steel plate shear walls with different post-tensioned beam-to-column rocking connections. Engineering Structures, 2019. 187: p. 43-56.

43. Moroder, D., et al., Seismic testing of post-tensioned Pres-Lam core walls using cross laminated timber. Engineering Structures, 2018. 167: p. 639-654.

44. Shu, Z., et al., Seismic design and performance evaluation of self-centering timber moment resisting frames. Soil Dynamics and Earthquake Engineering, 2019. 119: p. 346-357.

45. Henry, R., S. Sritharan, and J. Ingham, Finite element analysis of the PreWEC self-centering concrete wall system. Engineering Structures, 2016. 115: p. 28-41.

46. Clayton, P.M., et al., Comparison of web plate numerical models for self-centering steel plate shear wal/s. Earthquake Engineering \& Structural Dynamics, 2015. 44(12): p. 2093-2110.

47. Kramer, A., A.R. Barbosa, and A. Sinha, Performance of steel energy dissipators connected to crosslaminated timber wall panels subjected to tension and cyclic loading. Journal of Structural Engineering, 2015. 142(4): p. E4015013.

48. Erkmen, B. and A.E. Schultz, Self-centering behavior of unbonded, post-tensioned precast concrete shear walls. Journal of Earthquake Engineering, 2009. 13(7): p. 1047-1064.

49. Buchanan, A.H., Fire performance of timber construction. Progress in structural engineering and materials, 2000. 2(3): p. 278-289.

50. Schaffer, E., State of structural timber fire endurance. Wood and Fiber Science, 2007. 9(2): p. 145-170.

51. Collier, P. and A. Buchanan, Fire resistance of lightweight timber framed walls. Fire technology, 2002. 38(2): p. 125-145.

52. Lineham, S.A., et al., Structural response of fire-exposed cross-laminated timber beams under sustained loads. Fire Safety Journal, 2016. 85: p. 23-34.

53. Buchanan, A., B. Ostman, and A. Frangi, Fire resistance of timber structures. 2014: National Institute of Standards and Technology Gaithersburg.

54. Hadden, R.M., et al., Effects of exposed cross laminated timber on compartment fire dynamics. Fire Safety Journal, 2017. 91: p. 480-489.

55. Hasburgh, L., et al. Fire performance of mass-timber encapsulation methods and the effect of encapsulation on char rate of cross-laminated timber. in world conference on timber engineering, Vienna, Austria. 2016.

56. White, R.H., Charring rate of composite timber products. Proceedings Wood and Fire Safety, 2000: p. 353363.

57. Barber, D., Determination of fire resistance ratings for glulam connectors within US high rise timber buildings. Fire Safety Journal, 2017. 91: p. 579-585.

58. Cachim, P.B. and J.-M. Franssen, Assessment of Eurocode 5 charring rate calculation methods. Fire technology, 2010. 46(1): p. 169.

59. Zhang, J., et al., An experimental and numerical study on the charring rate of timber beams exposed to threeside fire. Science China Technological Sciences, 2012. 55(12): p. 3434-3444.

60. Ho, T.X., et al., Hybrid system of unbonded post-tensioned CLT panels and light-frame wood shear walls. Journal of Structural Engineering, 2016. 143(2): p. 04016171.

61. Oktavianus, Y., et al., Structural behaviour of prefabricated load bearing braced composite timber wall system. Engineering Structures, 2018. 176: p. 555-568. 
Bregulla, J., et al., Barriers to the enhanced use of wood in Europe: particular attention to the regulatory

63. O'Connor, J., et al., Wood use in nonresidential buildings: Opportunities and barriers. Forest products journal, 2004. 54(3).

64. Bengtson, A., Framing technological development in a concrete context: The use of wood in the Swedish construction industry. 2004.

65. Nord, T., Prefabrication strategies in the timber housing industry: a comparison of Swedish and Austrian markets. 2008, Luleå tekniska universitet.

66. Bayne, K. and S. Taylor, Attitudes to the use of Wood as a Structural Material in Non-residential Building Applications: Opportunities for Growth. Forest and Wood Products Research and Development Corporation, Victoria, Australia, 2006.

67. He, M., et al., Experimental investigation on lateral performance of timber-steel hybrid shear wall systems. Journal of Structural Engineering, 2013. 140(6): p. 04014029.

68. Hao, H., et al. Finite element analysis of structural insulated panel with OSB skins against windborne debris impacts. in Proceedings of 1st Pan-American congress on computational mechanics (PANACM), Buenos Aires, Argentina. 2015.

69. Meng, Q., et al., Failure behaviors of oriented strand board material under quasi-static and dynamic loads. Journal of Materials in Civil Engineering, 2017. 30(3): p. 04017297.

70. Chen, W. and H. Hao, Performance of structural insulated panels with rigid skins subjected to windborne debris impacts-Experimental investigations. Construction and Building Materials, 2015. 77: p. 241-252.

71. Egger Os'brace: The environmentally sustainable bracing panel. EGGER Building Products GmbH, Weiberndorf 206380 St. Johann in Tirol, Austria, 2018.

72. Brandner, R., et al., Cross laminated timber (CLT): overview and development. European Journal of Wood and Wood Products, 2016. 74(3): p. 331-351.

73. Orlowski, K., Review of Timber connections: Connector Plate, Cleats, Studies and Dovetail Connections. Advancements in Civil Engineering \& Technology, 2019. 3(4).

74. Veljkovic, M. and B. Johansson, Light steel framing for residential buildings. Thin-Walled Structures, 2006. 44(12): p. 1272-1279.

75. Bäckström, M., M. Al-Emrani, and R. Kliger, Timber-framed partition walls and their restraining effect on warp in built-in wall studs-Models for twist. Construction and Building Materials, 2009. 23(12): p. 35563563.

76. Orlowski, K., Assessment of Manufacturing Processes for Automated Timber-Based Panelised Prefabrication. Buildings, 2019. 9(5): p. 125.

77. Willmann, J., et al., Robotic timber construction - Expanding additive fabrication to new dimensions. Automation in Construction, 2016. 61: p. 16-23.

78. Sass, L., Synthesis of design production with integrated digital fabrication. Automation in construction, 2007. 16(3): p. 298-310.

79. Bock, T., The future of construction automation: Technological disruption and the upcoming ubiquity of robotics. Automation in Construction, 2015. 59: p. 113-121.

80. Orlowski, K., Automated manufacturing for timber-based panelised wall systems. Automation in Construction, 2020. 109: p. 102988.

81. Z. Zabihi, K.C., B. Samali, Modern trends in long span timber flooring systems. Incorporating Sustainable Practice in Mechanics and Structures of Materials, 2010. 903-907.

82. Holzer, S.M., J.R. Loferski, and D.A. Dillard, A review of creep in wood: Concepts relevant to develop longterm behavior predictions for wood structures. Wood and Fiber Science, 2007. 21(4): p. 376-392.

83. Hanhijärvi, A. and D. Hunt, Experimental indication of interaction between viscoelastic and mechano-sorptive creep. Wood Science and Technology, 1998. 32(1): p. 57-70.

84. Buchanan, A., et al., Multi-storey prestressed timber buildings in New Zealand. Structural Engineering International, 2008. 18(2): p. 166-173.

85. Newcombe, M., et al., Section analysis and cyclic behavior of post-tensioned jointed ductile connections for multi-story timber buildings. Journal of Earthquake Engineering, 2008. 12(S1): p. 83-110.

86. Chancellor, N.B., et al., Self-centering seismic lateral force resisting systems: High performance structures for the city of tomorrow. Buildings, 2014. 4(3): p. 520-548.

87. Janssens, A. and H. Hens. Condensation risk assessment. in Thermal Performance of the Exterior Envelopes of Buildings VII: Conference Proceedings. 1998.

88. Aelenei, D. and F.M. Henriques, Analysis of the condensation risk on exterior surface of building envelopes. Energy and Buildings, 2008. 40(10): p. 1866-1871.

89. Mumovic, D., et al., Condensation risk: comparison of steady-state and transient methods. Building Services Engineering Research and Technology, 2006. 27(3): p. 219-233.

90. Liu, J., H. Aizawa, and H. Yoshino, CFD prediction of surface condensation on walls and its experimental validation. Building and Environment, 2004. 39(8): p. 905-911. 
92. AS1720.2, Timber structures: Timber Properties. Standards Australia, 2006: p. 17.

93. AS/NZS1163, Cold-formed structural steel hollow section. Standards Australia, 2016. BD-023: p. 46.

94. EN, Wood-based panels-Characteristic values for structural design-Part 1: OSB, particleboards and fibreboards. European Committee for Standardization, Brussels, 2001: p. 9.

95. Egger EGGER OSB4 TOP - High Performance And Sustainability for elevated Wood Construction Requirements. EGGER Building Products GmbH, Weiberndorf 206380 St. Johann in Tirol, Austria, 2018.

96. Kenkyujo, T.S., Developing Strain Gauges and Instrument. Precise \& Flexible Strain Gauges. 8-2, MinamiOhi 6-Chome, Shinagawa-Ku, Tokyo 140-8560, Japan, 2017.

97. Che, B., Improved exact strip postbuckling analysis of anisotropic plate with combined load and edge cases. 2012, Cardiff University.

98. Fenner, P., Comparing the accuracy of VICONOPT to FEM for analysing aircraft wing skin type panels, in Aeronautical and Automotive Engineering. 2014, Loughborough University: Loughborough University.

99. Wittrick, W.H. and F. Williams, A general algorithm for computing natural frequencies of elastic structures. The Quarterly Journal of Mechanics and Applied Mathematics, 1971. 24(3): p. 263-284.

100. Wittrick, W.H. and F.W. Williams, Buckling and vibration of anisotropic or isotropic plate assemblies under combined loadings. International Journal of Mechanical Sciences, 1974. 16(4): p. 209-239.

101. Plank, R. and W. Wittrick, Buckling under combined loading of thin, flat-walled structures by a complex finite strip method. International Journal for Numerical Methods in Engineering, 1974. 8(2): p. 323-339.

102. ABAQUS, ABAQUS Analysis User's manual. Dassault Systemes, Vélizy-Villacoublay, France, 2009.

103. Budiwati, I.A.M., Finite Element Models of Post-Tensioned Masonry Column. Jurnal Ilmiah Teknik Sipil, 2008.

104. Oktavianus, Y., H.M. Goldsworthy, and E. Gad, Group behavior of double-headed anchored blind bolts within concrete-filled circular hollow sections under cyclic loading. Journal of Structural Engineering, 2017. 143(10): p. 04017140.

105. Huang, Y. and B. Young, The art of coupon tests. Journal of Constructional Steel Research, 2014. 96: p. 159175.

106. AS/NZS 2269.1, Plywood-Structural. Part 1: Determination of structural properties - Test methods. 2012, Standards Australia Limited/Standards New Zealand.

107. AS/NZS 4063.1, Characterization of structural timber. Part 1: Test methods. 2010, Standards Australia Limited/Standards New Zealand.

108. AS/NZS 4357.2, Structural laminated veneer lumber (LVL). Part 2: Determination of structural properties Test methods. 2006, Standards Australia Limited/Standards New Zealand.

109. Kováčiková, J., et al., Finite element analysis of timber beams with flaws in ECCOMAS Congress 2016-VII European Congress on Computational Methods in Applied Sciences and Engineering. 2016: Crete Island.

110. Plenzler, R., L. Ludwiczak-Niewiadomska, and P. Strzelecki, Elastic and strength properties of OSB layers. Drvna Industrija, 2017. 68(1): p. 3-9.

111. Portioli, F., et al., Numerical modeling of connections with timber pegs, in World Conference on Timber Engineering. 2010: Trentino, Italy.

112. Sandhaas, C. and J.W.G.v.d. Kuilen, Material model for wood HERON, 2013. 58(2/3): p. 171-191.

113. Thomas, W.H., Planar shear moduli of rigidity of an oriented strand board from bending and shear tests. Materials and Structures, 2004. 37(7): p. 480-484.

114. AS/NZS1720, Timber structures - Design Method Standards Australia GPO Box 476, Sydney, NSW 2001, Australia., 2010.

115. Buchanan, A.H., Timber design guide. 3rd ed. ed. 2007, University of Canterbury New Zealand Timber Industry Federation.

116. AS2269, Plywood - Structural: Test Specifications Standards Australia, 2008.

117. AS4063.1, Characterization of structural timber - Test methods. Standards Australia, 2010.

118. AS 1720.1, Timber structures. Part 1: Design methods. 2010, Standards Australia Limited: Sydney, Australia. 119. Sika, Product Data Sheet: Sikaflex-221. 2013, Sika Australia Pty Ltd: Australia.

120. Scheider, I. and W. Brocks. The effect of the traction separation law on the results of cohesive zone crack propagation analyses. in Key Engineering Materials. 2003. Trans Tech Publ.

121. Schober, K.-U. and K. Rautenstrauch. On the application of cohesive zone modeling in timber composite structures. in Proceedings of the 10th World Conference on Timber Engineering (WCTE 2008). 2008.

122. Derikvand, M. and H. Pangh, Adhesive bond strength. BioResources, 2016. 11(1): p. 354-364.

123. EN 302-1, Adhesives for load-bearing timber structures - Test methods - Part 1: Determination of longitudinal tensile shear strength. 2013, European Committee for Standardization.

124. ASTM D-905, Standard test method for strength properties of adhesive bonds in shear by compression loading. 1998, The American Society for Testing and Materials: USA.

125. Officials, I.C.o.B. Uniform building code. in International Conference of Building Officials. 1997. Whittier, CA: ICBO. 


\section{University Library}

\section{- M M I N E R VA A gateway to Melbourne's research publications}

Minerva Access is the Institutional Repository of The University of Melbourne

Author/s:

Orlowski, K

Title:

Verified and validated design curves and strength reduction factors for post-tensioned composite steel-timber stiffened wall systems

Date:

2020-02-01

\section{Citation:}

Orlowski, K. (2020). Verified and validated design curves and strength reduction factors for post-tensioned composite steel-timber stiffened wall systems. Engineering Structures, 204, https://doi.org/10.1016/j.engstruct.2019.110053.

Persistent Link:

http://hdl.handle.net/11343/241789 